\title{
Energía y riesgo-país: ¿permite la explotación de energías fósiles mejorar las calificaciones de riesgo-país?*
}

\author{
Silvia Iranzo Gutiérrez \\ Colegio Universitario de Estudios Financieros (CUNEF) \\ e Instituto de Estudios Bursátiles \\ Programa de Doctorado de Economía y Empresa. UNED
}

\begin{abstract}
Resumen
El presente artículo analiza la relación existente entre los indicadores de riesgo-país de las distintas regiones del mundo y su nivel de dependencia de las energías fósiles (petróleo, gas y carbón). La cuestión es relevante porque los países productores de estas energías son en su mayoría países emergentes o en desarrollo, que requieren inversiones extranjeras en el sector energético, para lo que es esencial mantener unos niveles de riesgo-país adecuados. Los análisis efectuados muestran que en algunas regiones se cumple la «maldición de los recursos», por la que la producción y exportación de energías fósiles conduce a un deterioro de los niveles de riesgo-país.

Palabras clave: riesgo-país, dependencia energética, energías fósiles, calificaciones de riesgo soberano, agencias de rating, EMBI global, clasificación de riesgo-país de la OCDE, indicadores de gobernanza.
\end{abstract}

Códigos JEL: E6, F21, F34, G15, O1, Q4.

\begin{abstract}
This article studies the relationship between country-risk indicators and fossil energy dependence (crude oil, natural gas and coal) for the different regions in the world. The matter is of great relevance, because fossil energy producers are for the most part emerging or developing countries, that rely to a great extent on foreign direct investments for exploration and development of the energy sector. FDI decisions in turn rely on analysis of country-risk. The theories of the «resource curse», whereby production and exports of fossil fuels lead to a deterioration of the exporting economy, work well with some of the findings of this article.

Keywords: country-risk, energy dependence, fossil energies, OECD sovereign country-risk classification, governance indicators.

JEL classification: E6, F21, F34, G15, O1, Q4.
\end{abstract}

\section{Introducción}

La pregunta planteada en el título tiene interés, porque la creencia popular dominante, posiblemente basada en el éxito en la explotación de los recursos minerales y energéticos de los grandes países avanzados como Estados Unidos o Reino Unido

* La autora agradece la ayuda y los comentarios recibidos de Ricardo Queralt (profesor de CUNEF), Nieves Arranz (profesora de la UNED) y Fernando Maravall (Técnico Comercial y Economista del Estado). 
en las fases iniciales de su desarrollo moderno, es que el descubrimiento de recursos energéticos constituye una fortuna para el país que los descubre ${ }^{1}$.

Lo cierto es que la producción de recursos energéticos permite incrementar la autosuficiencia energética y, por tanto, la seguridad del suministro energético. Por ejemplo, la Estrategia de Seguridad Energética de la Unión Europea (Comisión Europea, 2017) incluye, entre las medidas de largo plazo que deben adoptar los países de la Unión Europea, un incremento de la producción («sostenible») de energías fósiles. Por otro lado, la teoría económica ilustra sobre los efectos positivos derivados del comercio internacional y de la exportación (Mankiw, 2015)2 ${ }^{2}$, que lógicamente incluye energías fósiles. También la Organización Mundial del Comercio (OMC) recuerda los efectos beneficiosos del comercio internacional sobre el crecimiento económico (OMC, 2017). Y la exportación de recursos energéticos, como cualquier exportación, ejerce un impacto favorable el saldo de la balanza de pagos, los ingresos públicos, las entradas de divisas, el empleo, el PIB y, en definitiva, la renta y la riqueza.

Además, la producción y exportación de recursos energéticos como petróleo, gas y carbón constituye una importante vía de financiación del desarrollo, pues permite incrementar los ingresos por divisas reduciendo la necesidad de endeudamiento exterior, mejorar la recaudación tributaria (dada la posibilidad de establecer impuestos y cánones a la producción de estos recursos), reducir la dependencia energética del exterior, y promover la inversión extranjera directa en el sector energético y en la industria derivada del mismo (sectores eléctrico, químico, infraestructuras, etc).

En este trabajo, se presentarán primero los indicadores utilizados, así como los países y el periodo analizado. En segundo lugar, se realizará una breve descripción del mercado de las distintas fuentes energéticas, para conocer cuál es la importancia relativa de los tipos de energía y cuáles son los países productores y consumidores. En tercer lugar, se observará, con un enfoque estático, la relación entre los valores adoptados por los distintos indicadores de riesgo-país y la situación de dependencia o no de energías fósiles de cada región. En cuarto lugar, se realizará un estudio econométrico para valorar la medida en la que el grado de dependencia energética de cada región contribuye a explicar cada indicador de riesgo-país a lo largo del tiempo (periodo 2000-2015). Y por último se formularán algunas recomendaciones de política para los países productores y exportadores de energías fósiles.

${ }^{1}$ La explotación de recursos minerales, sobre todo el carbón, constituyó un elemento crucial del desarrollo de Gran Bretaña desde la Revolución Industrial en el siglo XVIII (NEAL y CAMERON, 2016), de Estados Unidos durante el siglo XIX y hasta mediados del xx, y de Alemania y Reino Unido desde finales del siglo XIX (VAN DER PLOEG, 2011). Quizá por ello, los descubrimientos de petróleo son objeto de celebración y de conmemoración en algunos lugares del mundo. Por ejemplo, el primer boom del petróleo en Texas (Estados Unidos) en el verano de 1894 (yacimiento de Corsicana) se sigue celebrando anualmente por los residentes locales (Derrick Day Chili \& BBQ Cook-Off). En Argentina, el 13 de diciembre de cada año se celebra el Día Nacional del Petróleo, en conmemoración del descubrimiento de petróleo ese mismo día de 1907 en la localidad de Comodoro Rivadavia. Los descubrimientos de gas en Perú en los primeros años 80, y de petróleo en Brasil en el «presal» a mediados de los años 2000, también fueron ampliamente celebrados.

${ }_{2}$ Algunos de estos efectos positivos son el aumento del excedente del consumidor y del productor, la reducción de costes merced a las economías de escala logradas mediante la ampliación del mercado, el aumento de la competencia y un mayor flujo internacional de ideas y conocimientos. 
Los resultados del trabajo son de especial relevancia, teniendo en cuenta la aparición de muchos países en los que se han realizado recientemente, y por primera vez, descubrimientos de yacimientos de energías fósiles, y van a convertirse en nuevos productores. Es el caso de Surinam y Guayana -petróleo offshore-, Mauritania y Senegal -petróleo y gas offshore-, Tanzania y Mozambique -gas offshore-, Kenia y Uganda -petróleo onshore- e Israel y Chipre -gas offshore- (Institut Français du Pétrole, 2016).

\section{Selección de indicadores, países y años}

\subsection{Indicadores}

Debido a su importancia en la producción de energía final y en los flujos comerciales mundiales, se han empleado las energías fósiles (petróleo, gas natural y carbón) para determinar el grado de dependencia energética. Es cierto que estas energías tenderán a declinar a largo plazo por su adverso impacto sobre el medio ambiente y el cambio climático. Esto será particularmente notable en el caso del carbón, pero hoy día su producción es necesaria, y de ahí consideración en este artículo. Por otro lado, la selección del petróleo, gas y carbón como recurso energético se justifica porque las restantes energías (nuclear, hidroeléctrica, eólica, solar) no son exportables en forma de energía primaria. Sí lo sería la energía final obtenida merced a las mismas (electricidad), pero las conexiones eléctricas entre países son por el momento muy escasas. Además, si bien las energías renovables están cobrando un protagonismo creciente como energía primaria, y esperablemente sustituirán a largo plazo a las energías fósiles, actualmente solo representan el 2,7 por 100 de la energía primaria mundial.

Las energías fósiles constituyen el 86 por 100 de la energía primaria mundial. Además, en el mix eléctrico, el petróleo, el gas natural y el carbón representaron en 2014, según la Organización para la Cooperación y el Desarrollo Económico -OCDE (Key World Energy Statistics 2016) de forma conjunta el 66,7 por 100 (petróleo 4,3 por 100, gas natural 21,6 por 100 y carbón 40,8 por 100). La exportación mundial de energías fósiles representó el 12,72 por 100 de los flujos comerciales mundiales en 2015, según el Banco Mundial (World Bank Data. Fuel Exports, 2015). Actualmente, el 32,57 por 100 de la producción de energías fósiles es objeto de exportación: se exporta el 45,3 por 100 de la producción de petróleo -sin considerar productos refinados-, el 29,3 por 100 del gas y el 20,7 por 100 del carbón (BP Statistical Review of World Energy, 2016).

Como expresión de la dependencia de energías fósiles, se ha seleccionado el indicador publicado por el Banco Mundial, denominado «Importaciones de energía, valor neto (\% del uso de energía)», o en inglés, Energy Imports, net (\% of energy use) (World Bank Data). Se calcula como la importación neta de energías fósiles (importación menos exportación) dividida por el consumo energético total de estas 
energías, expresado en porcentaje. Un signo negativo de este indicador implica que el país es exportador neto de energía, entendiendo por energía en lo sucesivo, a efectos de este artículo, las energías fósiles (por ejemplo, un valor de -200 supone que el país exporta en términos netos dos veces su consumo interno de los mismos). Un signo positivo supone que el país es importador neto de estos recursos (por ejemplo, un valor de 100 significa que el país debe importar todo su consumo interno de energía; un valor de 20 implica que el país debe importar en términos netos el 20 por 100 de la energía que consume). Como puede deducirse, este indicador puede adoptar cualquier valor en el tramo negativo (un país puede exportar muchas veces su consumo energético), y tan solo un valor comprendido entre 0 y 100 en el tramo positivo (ningún país importa más recursos que los que consume).

Como representativo de la solidez de la situación económico-financiera de los países, se ha optado por seleccionar el nivel de riesgo-país, medido a través de diversos indicadores, frente a otros indicadores como la tasa de crecimiento o la renta per cápita, por dos motivos. El primero es que el riesgo-país constituye un condicionante esencial para las decisiones de inversión extranjera en los países emergentes y en desarrollo (estos representan en conjunto la mayor parte de la producción mundial de energías fósiles), que requieren por lo general inversiones exteriores en el sector que incorporen tecnologías de extracción, desarrollo y distribución energética (Hayakawa, Kimura y Lee, 2011). El segundo es que los indicadores de riesgo-país tienen en cuenta prácticamente todos los indicadores económicos. Así, el riesgo-país es parte esencial del análisis de vigilancia de los países que realiza el FMI (Fondo Monetario Internacional) (Ahuja, Wiseman y Syed, 2017). Además, el riesgo-país requiere analizar factores políticos o culturales que, como es bien conocido, pueden afectar de manera crucial a la economía de un país. Emplear únicamente un indicador, como la tasa de crecimiento económico, tendría un alcance menor, por su volatilidad en el tiempo y porque no refleja necesariamente la solidez de la economía en el medio y largo plazo.

En rigor el riesgo-país representa el grado de confianza de la comunidad internacional en la capacidad de un país de honrar su deuda externa, pública o privada. Esta capacidad depende de múltiples factores, sobre todo económico-financieros y políticos. Sin ánimo de exhaustividad, pueden citarse los siguientes factores (Iranzo, 2008): en el campo económico, la tasa de crecimiento económico, renta per cápita, tasa de inflación, tipos de interés, saldo del sector público, nivel de la deuda pública, desarrollo del mercado local de bonos, calidad de las políticas monetaria y fiscal, grado de desigualdad, diversificación productiva, dependencia energética, tamaño del país, solvencia de las entidades de crédito y solidez del sistema financiero, saldo de la balanza de pagos, nivel y estructura de la deuda externa, controles de cambios, historial de devaluaciones, historial de pagos y de refinanciaciones de la deuda (en el Club de París o en otros ámbitos), o nivel de las reservas de divisas; en el campo político, la estabilidad política, la eficacia del gobierno, la fortaleza de las instituciones, el riesgo de conflictos internos, el riesgo geopolítico, el nivel de corrupción, o la cultura de pago de la deuda. 
El riesgo-país también incluye el riesgo asociado a la inversión extranjera directa, que incluye el riesgo de transferencia en el pago de los dividendos y el producto de la liquidación de las inversiones, el riesgo de confiscación, expropiación y nacionalización de las inversiones extranjeras, el riesgo de incumplimiento de los contratos y el riesgo de guerras, violencia política y catástrofes naturales (Iranzo, 2008). El riesgo asociado a la inversión extranjera directa depende de los mismos factores enunciados en el párrafo anterior.

Los indicadores específicos de riesgo-país que se han tenido en consideración son los siguientes:

a) La clasificación de riesgo-país de la OCDE

La OCDE, a través del subgrupo de expertos en materia de riesgo-país, elabora una clasificación, en función del grado de riesgo-país de prácticamente todos los países del mundo (solo quedan excluidos de clasificación los países muy pequeños, que normalmente no reciben apoyo oficial de créditos a la exportación). Esta clasificación es pública y constituye una referencia importante para los estudiosos del riesgo-país. La clasificación califica a los países entre «0» (mejor riesgo-país) y «7» (peor riesgo-país) ${ }^{3}$.

b) Las calificaciones de riesgo soberano (rating soberano) a largo plazo en moneda extranjera de las tres principales agencias de calificación de riesgos

Se han considerado las calificaciones de riesgo soberano a largo plazo en moneda extranjera de las agencias Moody's, Standard \& Poor's y Fitch, que representan el 95 por 100 de todas las calificaciones de riesgo mundiales.

Se entiende por «riesgo soberano» el riesgo de impago de la deuda de los estados, o de entidades garantizadas por ellos. El impago de la deuda soberana puede producirse por la falta de ingresos públicos, por la carencia o insuficiencia de divisas, o porque el gobierno carezca de voluntad de pago por factores políticos de diversa índole.

\footnotetext{
${ }^{3}$ El método econométrico utilizado por la OCDE para efectuar su clasificación de riesgo-país es el modelo, denominado Country Risk Assessment Model (CRAM), que combina un planteamiento cuantitativo de tipo econométrico (experiencia de pagos reportado por los Participantes del Consenso de la OCDE, situación financiera, y situación económica según la valoración del Fondo Monetario Internacional, sobre todo) con valoraciones cualitativas. El resultado de la aplicación del modelo es la clasificación de cada país en una de ocho categorías de riesgo, numeradas de «0» a «7», siendo «0» la clasificación correspondiente a los países de menor riesgo (los de «renta alta» según los criterios de renta per cápita del Banco Mundial), y «7» la clasificación de los países con mayor riesgo. El principal objetivo de la clasificación es servir para determinar el nivel mínimo de primas de seguro de crédito que las agencias de crédito a la exportación (Export Credit Agencies, ECAs) deben cobrar en sus contratos de seguro para cada categoría de riesgo. La clasificación se somete a revisión continua en el seno del subgrupo de expertos en materia de riesgo-país, que como mínimo debe revisar la clasificación una vez al año o cada vez que surge un cambio «fundamental» en la situación del país.
} 
Con objeto de posibilitar la realización de operaciones numéricas con estas calificaciones soberanas, cada rating soberano ha sido convertido en un número mediante una tabla de correspondencia en la que el número asignado a cada rating está comprendido entre «0» (peor rating) y «23» (mejor rating) (Cuadro 1 ).

\section{CUADRO 1 \\ TABLA DE CORRESPONDENCIAS DE LOS RATINGS SOBERANOS \\ A LARGO PLAZO}

\begin{tabular}{|c|c|c|c|c|}
\hline & $\begin{array}{c}\text { Núnero asignado } \\
\text { a efectos del } \\
\text { presente trabajo }\end{array}$ & Moody's & $\begin{array}{c}\text { Standard \& } \\
\text { Poor's }\end{array}$ & Fitch \\
\hline \multirow{10}{*}{$\begin{array}{l}\text { Grado de } \\
\text { inversión }\end{array}$} & 23 & Ааa & AAA & AAA \\
\hline & 22 & Aa1 & AA+ & $\mathrm{AA}+$ \\
\hline & 21 & $\mathrm{Aa} 2$ & AA & $\mathrm{AA}$ \\
\hline & 20 & Aa3 & AA- & AA- \\
\hline & 19 & A1 & $\mathrm{A}+$ & $\mathrm{A}+$ \\
\hline & 18 & A2 & A & A \\
\hline & 17 & A3 & A- & A- \\
\hline & 16 & Baa1 & $\mathrm{BBB}+$ & $\mathrm{BBB}+$ \\
\hline & 15 & Baa2 & $\mathrm{BBB}$ & $\mathrm{BBB}$ \\
\hline & 14 & Baa3 & BBB- & BBB- \\
\hline \multirow{13}{*}{$\begin{array}{c}\text { Nivel } \\
\text { especulativo }\end{array}$} & 13 & Ba1 & $\mathrm{BB}+$ & $\mathrm{BB}+$ \\
\hline & 12 & $\mathrm{Ba} 2$ & $\mathrm{BB}$ & BB \\
\hline & 11 & $\mathrm{Ba} 3$ & BB- & BB- \\
\hline & 10 & $\mathrm{~B} 1$ & $\mathrm{~B}+$ & $\mathrm{B}+$ \\
\hline & 9 & B2 & $\mathrm{B}$ & B \\
\hline & 8 & B3 & B- & B- \\
\hline & 7 & Caa1 & $\mathrm{CCC}+$ & $\mathrm{CCC}+$ \\
\hline & 6 & $\mathrm{Caa} 2$ & $\mathrm{CCC}+$ & $\mathrm{CCC}$ \\
\hline & 5 & Caa3 & $\mathrm{CCC}+$ & $\mathrm{CCC}-$ \\
\hline & 4 & $\mathrm{Ca}$ & $\mathrm{CC}$ & $\mathrm{CC}$ \\
\hline & 3 & $\mathrm{C}$ & $\mathrm{C}$ & $\mathrm{C}$ \\
\hline & 2 & & SD & \\
\hline & 1 & & $\mathrm{D}$ & $\mathrm{D}$ \\
\hline
\end{tabular}

FUENTE: Moody's, Standard \& Poor's, Fitch y elaboración propia. 


\section{c) EMBI Global de JP Morgan}

El índice EMBI Global es el Índice Global de Bonos de Mercados Emergentes (en inglés, JP Morgan Emerging Market Bond Index Global, o EMBI Global). Es elaborado por JP Morgan, un banco norteamericano de carácter global. Mide la rentabilidad total de instrumentos de deuda en moneda extranjera de países emergentes negociados en los mercados financieros ${ }^{4}$.

\section{d) Indicadores de gobernanza del Banco Mundial (Worldwide Governance Indicators, WGI)}

Los indicadores WGI no son propiamente indicadores de riesgo-país, ya que contemplan solo una vertiente parcial de dicho riesgo: la calidad de la gobernanza. Sin embargo, se han empleado en algún caso a lo largo del trabajo para ayudar a explicar determinados resultados ${ }^{5}$.

\subsection{Periodo temporal}

El análisis se refiere al periodo 2000-2015, que es suficientemente amplio y reciente para que las conclusiones tengan validez y sean de interés en el momento actual. No se han incluido datos anteriores a 2000 porque el número de observaciones era muy escaso, tanto para el EMBI Global como para los ratings soberanos. Para los ejercicios 2015 y posteriores, apenas existían todavía, en el momento de escribir estas líneas, datos del Banco Mundial sobre dependencia energética.

${ }^{4}$ El EMBI (Emerging Market Bond Index) se introdujo en 1992, cubriendo solamente bonos Brady. El EMBI+, creado con posterioridad, incluía además empréstitos y eurobonos de valor nominal pendiente de vencimiento superior a $500 \mathrm{M}$ de dólares USA, que cumplían una serie de condiciones de liquidez en los mercados secundarios. El EMBI Global constituye una versión ampliada del EMBI+. El EMBI global define los mercados emergentes utilizando una combinación de la clasificación por renta per cápita del Banco Mundial y el historial de reestructuración de la deuda de cada país. Asimismo, los requisitos de liquidez en los mercados secundarios son menos estrictos en el caso del EMBI Global que en el EMBI+, por lo que aquel incluye un número mayor de emisiones de deuda de países emergentes. En el EMBI Global están representados unos 27 países. Desde 2005, el FMI solo incluye el EMBI Global en su informe Global Financial Stability Report (ya no incluye el EMBI+), debido a su carácter más representativo.

${ }^{5}$ Los WGI se basan en encuestas realizadas a institutos, servicios de estudios, ONG, organizaciones internacionales y empresas privadas, y no reflejan necesariamente las opiniones del Banco Mundial, de sus órganos de gobierno o de sus países miembros. Los indicadores WGI valoran seis áreas de gobernanza: estabilidad política y ausencia de violencia o de terrorismo, sufragio libre y universal y libertad de expresión, de prensa y de asociación; eficacia de la acción de gobierno; calidad regulatoria; seguridad jurídica; control de la corrupción. Cada una de estas áreas es valorada entre -2,5 (gobernanza débil) y +2,5 (gobernanza fuerte). Con objeto de que estos valores se encuentren en la escala positiva, se han recalculado sumando 2,50 a cada valor, y así obtener una escala de «0» a «5», mejorando así su operatividad. Además, para cada país y año se ha calculado la media aritmética de la valoración de cada una de las referidas seis áreas de gobernanza. Los compiladores de los datos y autores del informe sobre gobernanza mundial, con apoyo financiero del Banco Mundial, son Daniel Kaufmann (Natural Resource Governance Institute -NRGI- y Brookings Institution) y Aart Kraay (World Bank Development Research Group). 


\section{3. Ámbito geográfico}

Los países analizados son todos los del mundo para los que existen datos de dependencia energética e indicadores de riesgo-país. Para algunos indicadores de riesgo-país, como el EMBI Global y los ratings soberanos, se ha dispuesto de un menor número de observaciones que en el caso de la clasificación de riesgo-país de la OCDE o de los WGI del Banco Mundial. La razón es que tan solo disponen de EMBI Global los países que han realizado emisiones de deuda en moneda extranjera en los mercados internacionales. Por otro lado, disponen de rating soberano no solamente aquellos países que lo han solicitado a alguna de las agencias de rating referidas (estos países suelen coincidir con aquellos que han realizado emisiones de bonos en los mercados internacionales), sino también algunos países que han recibido una calificación de riesgo soberano sin haberlo solicitado (unsolicited credit ratings).

Los países han sido objeto de agrupación por regiones, empleando la distribución regional que emplea el FMI en sus informes anuales World Economic Outlook (Fondo Monetario Internacional, 2017), que divide a los países en siete regiones ${ }^{6}$.

\section{Principales países productores de energías fósiles. Evolución del consumo y la producción}

El Gráfico 1 muestra el consumo total de energía primaria para el periodo 20002015, detallando las distintas fuentes energéticas. Se ha optado por reflejar el consumo en lugar de la producción, ya que para todas las fuentes distintas de las energías fósiles (nuclear, hidroelectricidad y renovables -solar y eólica-), el dato disponible

6 África subsahariana: Angola, Benín, Botsuana, Burkina Faso, Burundi, Cabo Verde, Camerún, Chad, Comoras, República del Congo, Costa de Marfil, Eritrea, Etiopía, Gabón, Gambia, Ghana, Guinea Bissau, Guinea Ecuatorial, Guinea-Conakry, Kenia, Lesoto, Liberia, Madagascar, Malawi, Mali, Mauricio, Mozambique, Namibia, Níger, Nigeria, República Centroafricana, República Democrática del Congo, Ruanda, Santo Tomé y Príncipe, Senegal, Seychelles, Sierra Leona, Somalia, Suazilandia, Sudáfrica, Sudán del Sur, Tanzania, Togo, Uganda, Zambia y Zimbabue. Latinoamérica y Caribe: Antigua y Barbuda, Argentina, Aruba, Bahamas, Barbados, Belice, Bolivia, Brasil, Chile, Colombia, Costa Rica, Cuba, Curazao, Dominica, Ecuador, El Salvador, Granada, Guatemala, Guayana, Haití, Honduras, Jamaica, México, Nicaragua, Panamá, Paraguay, Perú, República Dominicana, San Cristóbal y Nieves, Santa Lucía, San Vicente y Granadinas, Surinam, Trinidad y Tobago, Uruguay y Venezuela. Asia emergente y en desarrollo: Bangladesh, Bután, Brunéi Darusalam, Camboya, China, Corea del Norte, Fiyi, Filipinas, India, Indonesia, Islas Marshall, Islas Salomón, Kiribati, Laos, Malasia, Maldivas, Micronesia, Mongolia, Myanmar, Nepal, Palaos, Papúa Nueva Guinea, Samoa, Sri Lanka, Tailandia, Timor Oriental, Tonga, Tuvalu, Vanuatu y Vietnam. Comunidad de Estados Independientes (CEI): Armenia, Azerbaiyán, Bielorrusia, Georgia, Kazajistán, Kirguistán, Moldavia, Rusia, Tayikistán, Turkmenistán, Ucrania y Uzbekistán. Europa emergente y en desarrollo: Albania, Bosnia-Herzegovina, Bulgaria, Croacia, Hungría, Kosovo, Macedonia (FYROM), Montenegro, Polonia, Rumanía, Serbia y Turquía. Países avanzados: Alemania, Australia, Austria, Bélgica, Canadá, Chipre, Corea del Sur, Dinamarca, Eslovaquia, Eslovenia, España, Estados Unidos, Estonia, Finlandia, Francia, Grecia, Hong Kong (China), Irlanda, Islandia, Israel, Italia, Japón, Letonia, Lituania, Luxemburgo, Macao (China), Malta, Noruega, Nueva Zelanda, Países Bajos, Portugal, Puerto Rico, Reino Unido, República Checa, San Marino, Singapur, Suecia, Suiza y Taiwán (Provincia de China). Países MENA (Middle East and North Africa): Afganistán, Arabia Saudí, Argelia, Bahréin, Yibuti, Emiratos Árabes Unidos, Egipto, Gaza y Cisjordania, Irán, Irak, Jordania, Kuwait, Líbano, Libia, Marruecos, Mauritania, Omán, Pakistán, Qatar, Siria, Sudán, Túnez y Yemen. 


\section{GRÁFICO 1 \\ CONSUMO MUNDIAL DE ENERGÍA PRIMARIA 2000-2015 \\ (En millones de toneladas equivalentes de petróleo, TEP)}

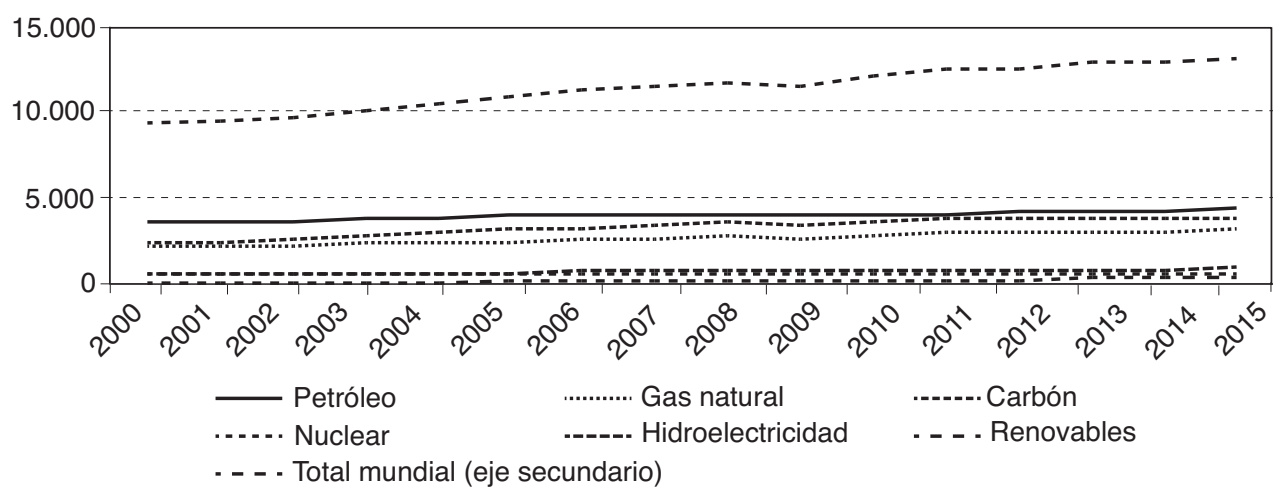

FUENTE: BP Statistical Review of World Energy, junio de 2016, y elaboración propia.

se refiere al consumo, que por motivos técnicos coincide prácticamente con la producción (consumo y producción solo difieren en la variación de stocks). Por ejemplo, en 2015 el consumo total de petróleo fue de 4.331,3 millones de toneladas, frente a una producción de 4.361,9 millones de toneladas. La diferencia del segundo respecto al primero fue de tan solo el 0,7 por 100 .

El gráfico refleja la preeminencia absoluta de las energías fósiles en la distribución del consumo mundial de energía primaria, al representar conjuntamente el 86 por 100 del total, correspondiendo el 33 por 100 al petróleo, el 30 por 100 al carbón y el 23,8 por 100 al gas natural. A gran distancia se encuentran las demás fuentes energéticas: la hidroelectricidad representa el 6,8 por 100 del total de consumo de energía primaria, la energía nuclear el 4,4 por 100, y las renovables (eólica y solar principalmente) tan solo el 2,7 por 100 .

Los Gráficos 2 y 3 muestran, respectivamente, cómo ha evolucionado la producción de petróleo y de gas natural de los principales países productores en los últimos 15 años.

De los datos del Gráfico 1 se desprende, primero, que la producción mundial de petróleo no ha dejado de aumentar en los últimos 15 años en respuesta a una mayor demanda. Pasó de una producción diaria de 74,9 millones de barriles en el año 2000 a 91,7 millones en 2015, lo que representa un aumento del 22,35 por 100. En segundo lugar, se aprecian diferentes comportamientos en la producción de algunos de los países contemplados en el Gráfico 2. Todos los países considerados aumentaron su producción de petróleo en los últimos 15 años (salvo en 2008-2009, los años peores de la Gran Recesión), con dos excepciones: Venezuela e Irán.

El Gráfico 3 refleja un incremento sustancial y sostenido durante el periodo considerado (del 46,2 por 100) de la producción mundial de gas natural, en respuesta a una mayor demanda de este combustible, debido a su mejor consideración desde el punto de vista medioambiental con respecto a las demás energías fósiles. La única 


\section{GRÁFICO 2 \\ PRODUCCIÓN MUNDIAL DE PETRÓLEO. LOS 10 PRIMEROS PAÍSES PRODUCTORES \\ (En miles de barriles diarios)}

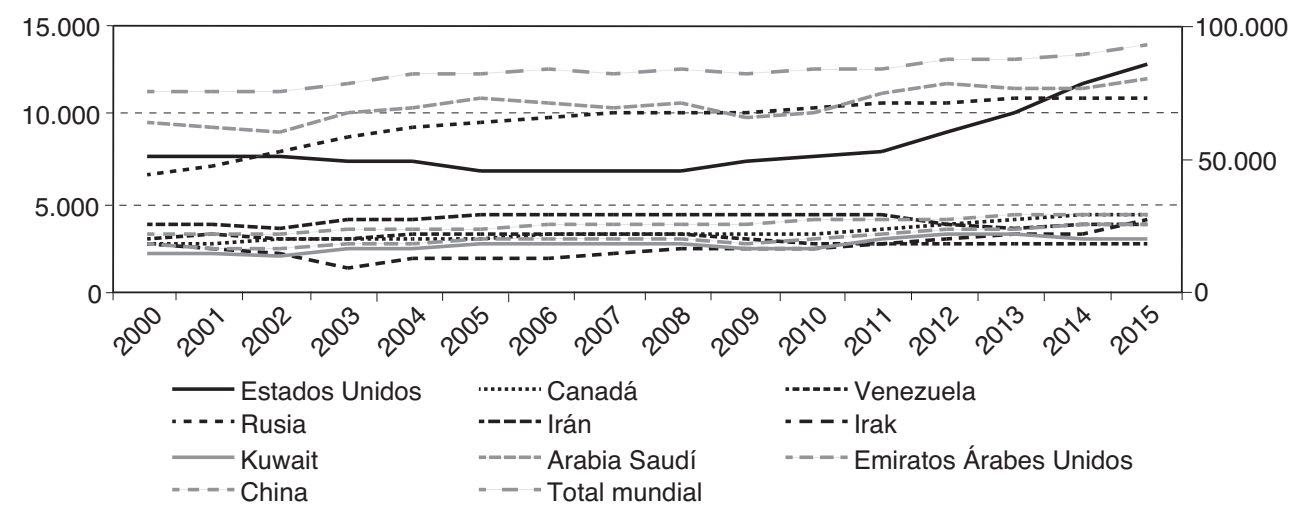

FUENTE: BP Statistical Review of World Energy, junio de 2016, y elaboración propia.

\section{GRÁFICO 3}

\section{PRODUCCIÓN MUNDIAL DE GAS NATURAL. LOS 10 PRIMEROS PAÍSES \\ PRODUCTORES}

(En miles de millones de metros cúbicos, BCM)

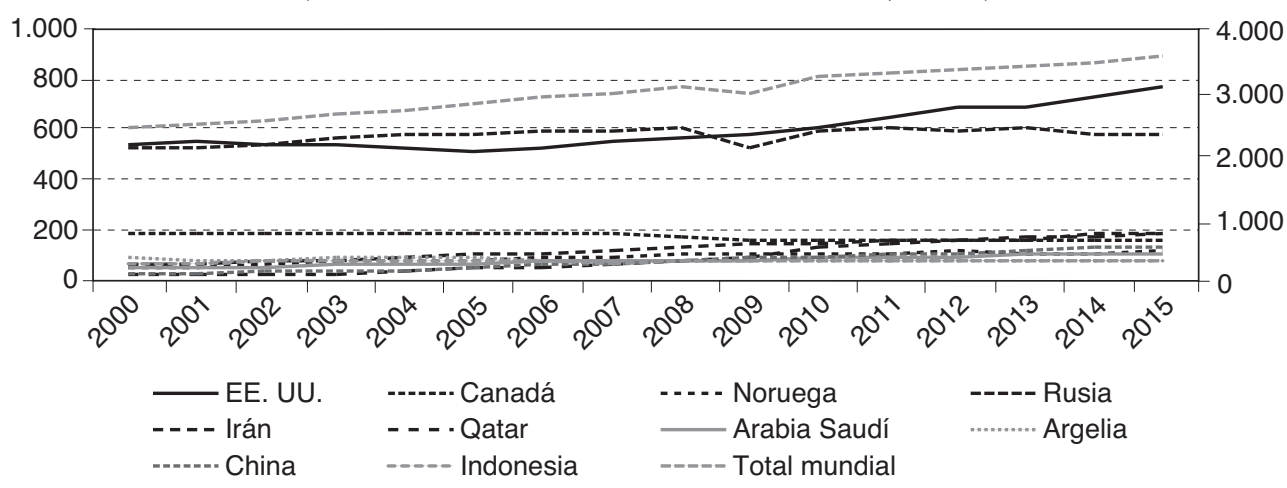

FUENTE: BP Statistical Review of World Energy, junio de 2016, y elaboración propia.

excepción a este comportamiento fue el periodo 2008-2009, debido a la caída de la demanda provocada por la Gran Recesión.

Por países, nuevamente Estados Unidos destaca por la expansión de su producción de gas durante el periodo 2000-2015, con un incremento total del 41,3 por 100 a lo largo del periodo contemplado. El motivo fue, al igual que en el caso del petróleo, el auge de la producción de gas mediante la técnica de fraqueo (fractura hidráulica), que ha llevado al país a desplazar a Rusia como primer productor mundial a partir de mediados de 2008 . 
El Gráfico 4 muestra la producción de carbón durante el periodo de referencia. La producción mundial ha evolucionado al alza desde el comienzo del periodo hasta el año 2013, con un descenso a partir de entonces. En el último año considerado, la producción cayó un 4 por 100, y la participación del carbón en el consumo total de energía primaria se redujo hasta el 29,2 por 100, el porcentaje más bajo desde 2005 . La explicación a este comportamiento se encuentra en China, que ya supone el 47 por 100 de la producción mundial de carbón, desde cerca del 30 por 100 en el año 2000. En este país llama la atención el desarrollo vertiginoso de la industria del carbón hasta el año 2013 (la producción casi se triplicó entre 2000 y 2013), momento a partir del cual inició un movimiento de descenso como consecuencia de un giro de la política energética china hacia un modelo más sostenible energéticamente.

El Gráfico 5 muestra los precios medios anuales de las energías fósiles durante el periodo 2000-2015. Como se observa, las tres fuentes energéticas mantienen tendencias parecidas (con algunos decalajes en el tiempo). Es lógico ya que el precio del gas en los contratos a largo plazo está muy indiciado al petróleo y, por otro lado, gas natural y carbón compiten como energía primaria en la producción de electricidad.

\section{GRÁFICO 4 \\ PRODUCCIÓN MUNDIAL DE CARBÓN. LOS 10 PRIMEROS PAÍSES PRODUCTORES \\ (En millones de toneladas)}

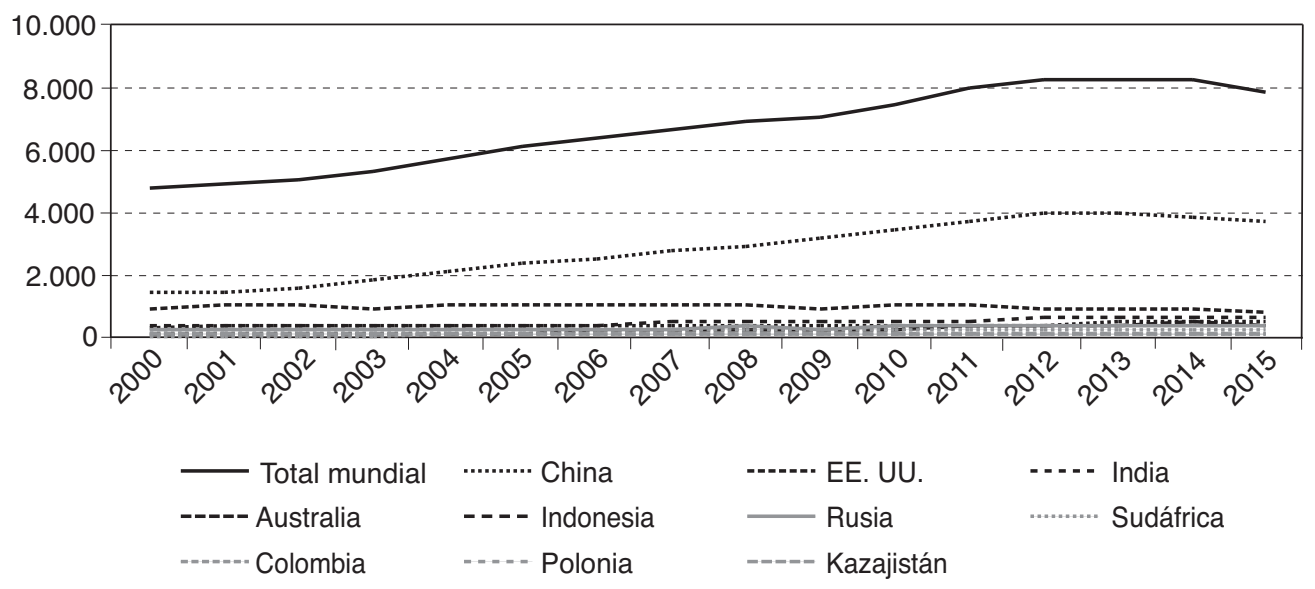

FUENTE: BP Statistical Review of World Energy, junio de 2016, y elaboración propia. 


\section{GRÁFICO 5}

\section{PRECIOS DEL PETRÓLEO, GAS Y CARBÓN}

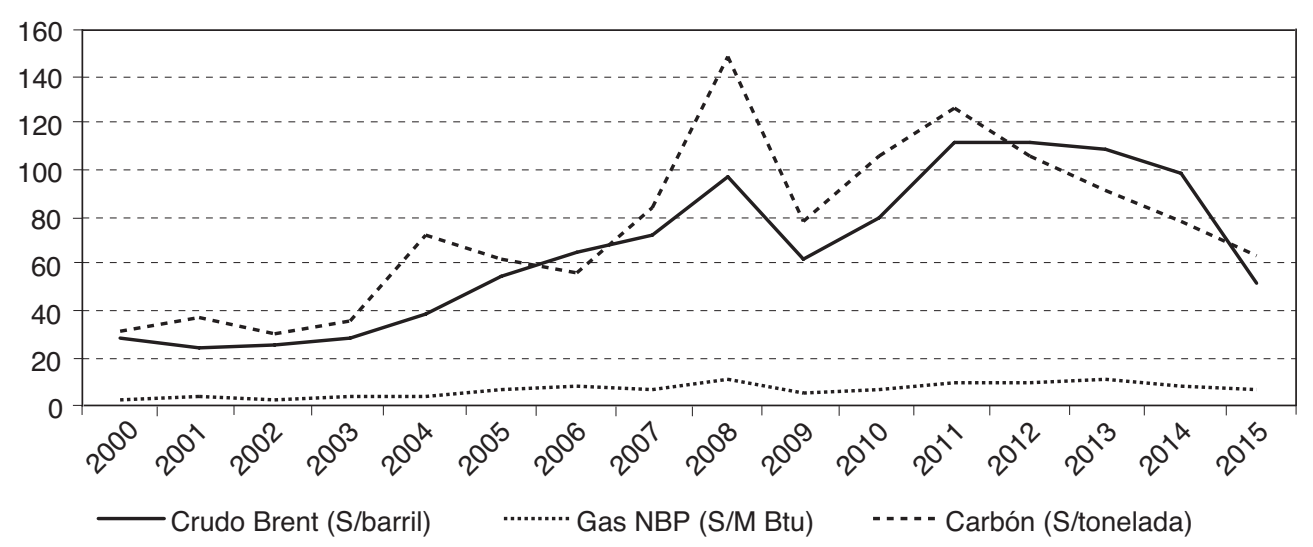

FUENTE: BP Statistical Review of World Energy, junio de 2016, y elaboración propia.

Los precios de las energías fósiles han variado a lo largo de cuatro fases diferenciadas.

- La primera fase comprende el periodo 2000-2008, al comienzo del cual los precios eran bajos, para escalar de forma continuada en respuesta a la demanda pujante de China, cuyo fuerte crecimiento económico en ese periodo requirió un consumo creciente de energía, conduciendo a excesos de demanda con el alza consiguiente en los precios.

- La segunda fase se produce desde comienzos de 2008 hasta mediados de 2009, en que se produjo la Gran Recesión. Esta condujo a un marcado descenso de los precios por la menor demanda.

- La tercera fase, desde 2009 hasta 2014, fue de recuperación de los precios, por la evolución positiva de la demanda conforme las economías iban saliendo de la crisis.

- La cuarta fase se inició en 2014, cuando los precios iniciaron una tendencia de descenso en respuesta a los excesos de oferta (de tres millones de barriles diarios en el caso del petróleo, según la AIE), ocasionados por el retroceso de la demanda en China, cuyo crecimiento inició una desaceleración, y el aumento de oferta (shale, etc).

Las variaciones de precios conducen a cambios en los ingresos de los países productores de energías fósiles, que en algunos casos son el origen de graves recesiones. Es el caso de Rusia y Brasil en 2015 y 2016, países en los que el descenso de los precios del petróleo, gas, y otras materias primas condujo a un retroceso económico que ha dañado seriamente a esas economías. En los países del Golfo Pérsico, el descenso del precio del petróleo ha llevado a una reducción de ingresos por la venta de petróleo de unos 300.000 millones de dólares en 2015. 


\section{El riesgo-país y la dependencia energética: evolución en el tiempo del riesgo-país en los países dependientes y no dependientes de la energía importada}

En este apartado serán objeto de presentación las conclusiones obtenidas de la observación de los datos de riesgo-país en función de la condición de dependencia energética o no de los países, agrupados por regiones.

El criterio que se ha utilizado para calificar a un país como dependiente energéticamente es que el indicador «Importaciones de energía, valor neto (\% del uso de energía)», descrito en párrafos anteriores, sea como máximo del 20 por 100, esto es, que el país dependa de la energía importada como máximo en un 20 por 100 de su consumo interno de energía. Países productores (y exportadores en algunos casos) de energía tan destacados como Brasil, Argentina, Estados Unidos o China se incluyen como no dependientes energéticamente empleando el criterio citado. Reducir el umbral del 20 por 100 los excluiría, lo que restaría representatividad a la muestra 7 .

Para cada una de las regiones consideradas, se ha calculado la media ponderada por el PIB de cada indicador de riesgo-país ${ }^{8}$, y ello para cada uno de los años considerados. Se ha estimado que la media ponderada arroja valores más representativos de la realidad del riesgo en cada región que la media simple. El empleo de esta hubiese otorgado la misma importancia a países muy divergentes en tamaño y relevancia, como por ejemplo Islas Fiyi y China dentro de la región de Asia emergente, o Brasil y la isla de Aruba dentro de la región de Latinoamérica. Europa emergente no ha sido objeto de análisis en este apartado 4, dado que ninguno de los países que integran esta región puede considerarse no dependiente energéticamente según el criterio empleado.

El análisis realizado para el indicador EMBI Global no ha arrojado resultados consistentes a lo largo del tiempo porque, de una parte, se trata de un indicador extremadamente volátil, acusando variaciones muy significativas en respuesta a cualquier incidencia en los mercados y, de otra parte, y sobre todo, porque el número de observaciones es escaso, ya que únicamente disponen de EMBI Global aquellos países emergentes que han realizado emisiones en los mercados internacionales. Por ejemplo, en la región de África subsahariana, en 2006 (año central de la serie temporal) solo había realizado emisiones internacionales un país, Sudáfrica. En 2014 habían realizado emisiones internacionales 14 países de esta región, de

${ }^{7}$ Los países no dependientes energéticamente, de acuerdo con el criterio del 20 por 100 como máximo de importaciones energéticas, son los siguientes. Países avanzados: Australia, Canadá, Dinamarca, Estados Unidos, Noruega y Países Bajos. Comunidad de Estados Independientes (CEI): Azerbaiyán, Kazajstán, Rusia, Turkmenistán y Uzbekistán. Asia emergente y en desarrollo: Brunéi Darusalam, China, Indonesia, Malasia, Mongolia, Myanmar y Vietnam. Europa emergente y en desarrollo: Ninguno. Latinoamérica y Caribe: Argentina, Bolivia, Brasil, Colombia, Ecuador, México, Perú, Trinidad y Tobago y Venezuela. Países MENA: Arabia Saudí, Argelia, Bahréin, Emiratos Árabes Unidos, Egipto, Irán, Irak, Kuwait, Libia, Omán, Qatar, Sudán y Yemen. África subsahariana: Angola, Congo, Gabón, Guinea Ecuatorial, Nigeria, Sudáfrica y Sudán del Sur.

${ }^{8}$ Para realizar la ponderación se han empleados datos sobre PIB de cada país ofrecidos por el Banco Mundial (World Bank Data, GDP current US\$). 
los 50 pertenecientes a la misma. En cambio, para el indicador de rating soberano, existían para la mencionada región 15 y 23 observaciones en 2006 y 2014, respectivamente. Para el indicador Clasificación de riesgo-país de la OCDE, existían 41 y 46 observaciones en 2006 y 2014, respectivamente. Por lo antedicho, no van a ser objeto de comentario los resultados del análisis para el indicador EMBI Global.

A continuación, se exponen los resultados del análisis para el periodo 2000-2015, con sus representaciones gráficas respectivas, para cada uno de los dos indicadores de riesgo, clasificación de riesgo-país de la OCDE y calificación de riesgo soberano de las agencias de rating. El resumen de dichos resultados está recogido en el Cuadro 2.

\subsection{Clasificación de riesgo-país de la OCDE}

En Latinoamérica los países dependientes energéticamente están mejor clasificados por la OCDE que los no dependientes, de forma más pronunciada a partir de 2013, y con excepción del periodo 2004-2008 (recuérdese que la clasificación de riesgo-país de la OCDE, comprendida entre «0»y «7», otorga calificaciones tanto más elevadas cuando mayor es el riesgo). En esta región, la diferencia a favor de los dependientes es del 12,8 por 100 respecto a la clasificación media de la región, durante el periodo 2009-2015.

En el resto de las regiones, Asia emergente y en desarrollo, África subsahariana, países CEI y países avanzados, los no dependientes están mejor clasificados que los dependientes. Las diferencias entre ambos tipos de países son del 39,54 por 100, 29,1 por $100,61,1$ por 100 y 187 por 100 , respectivamente, para las cuatro regiones mencionadas.

Los Gráficos 6 a 11 reflejan cuanto se acaba de comentar.

\section{GRÁFICO 6}

CLASIFICACIÓN OCDE RIESGO-PAÍS: ÁFRICA SUBSAHARIANA.

PAÍSES DEPENDIENTES Y NO DEPENDIENTES ENERGÉTICAMENTE

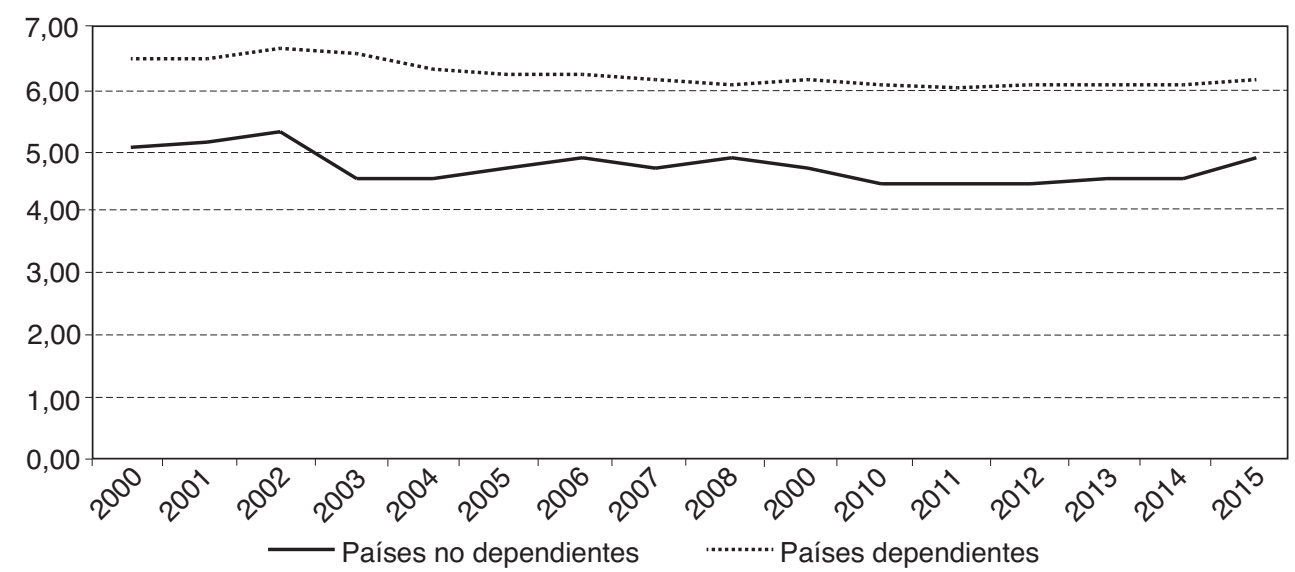

FUENTE: OCDE, Banco Mundial y elaboración propia. 


\section{GRÁFICO 7}

CLASIFICACIÓN OCDE RIESGO-PAÍS: ASIA EMERGENTE Y EN DESARROLLO. PAÍSES DEPENDIENTES Y NO DEPENDIENTES ENERGÉTICAMENTE

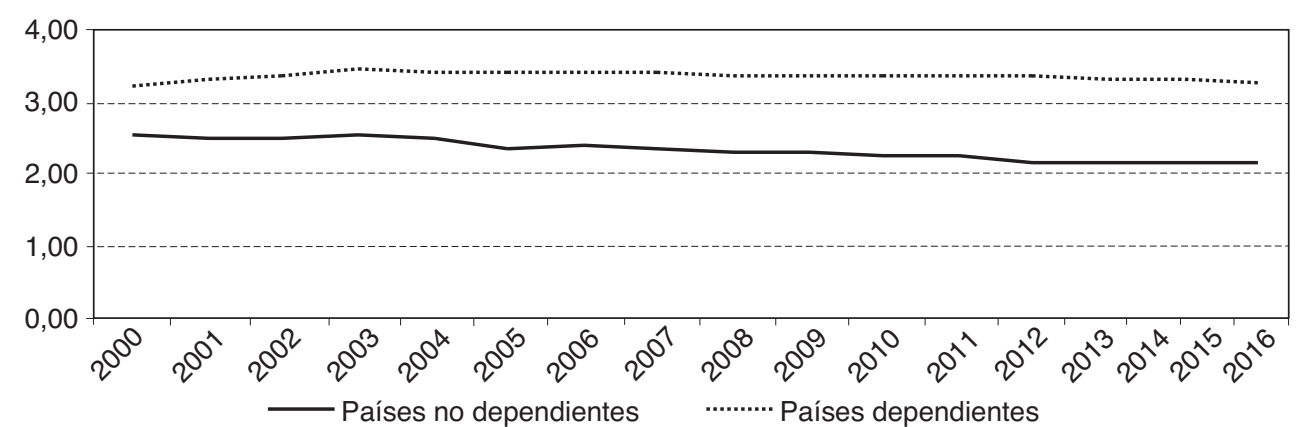

FUENTE: OCDE, Banco Mundial y elaboración propia.

\section{GRÁFICO 8}

CLASIFICACIÓN OCDE RIESGO-PAÍS: LATINOAMÉRICA Y CARIBE. PAÍSES DEPENDIENTES Y NO DEPENDIENTES ENERGÉTICAMENTE

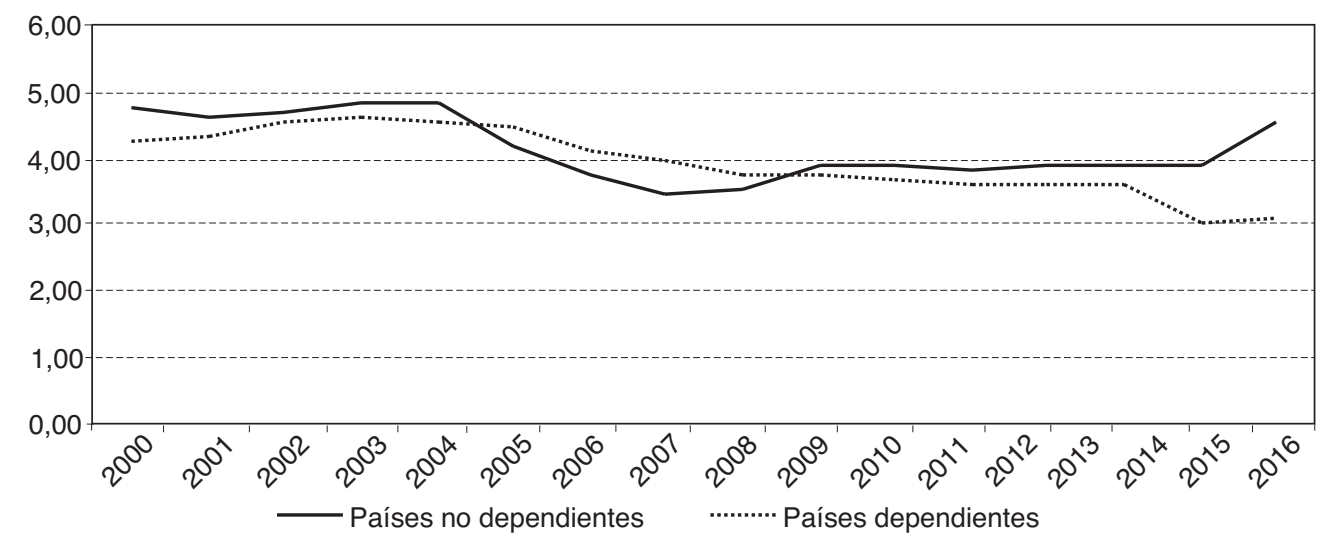

FUENTE: OCDE, Banco Mundial y elaboración propia. 


\section{GRÁFICO 9}

CLASIFICACIÓN OCDE RIESGO-PAÍS: CEI. PAÍSES DEPENDIENTES Y NO DEPENDIENTES ENERGÉTICAMENTE

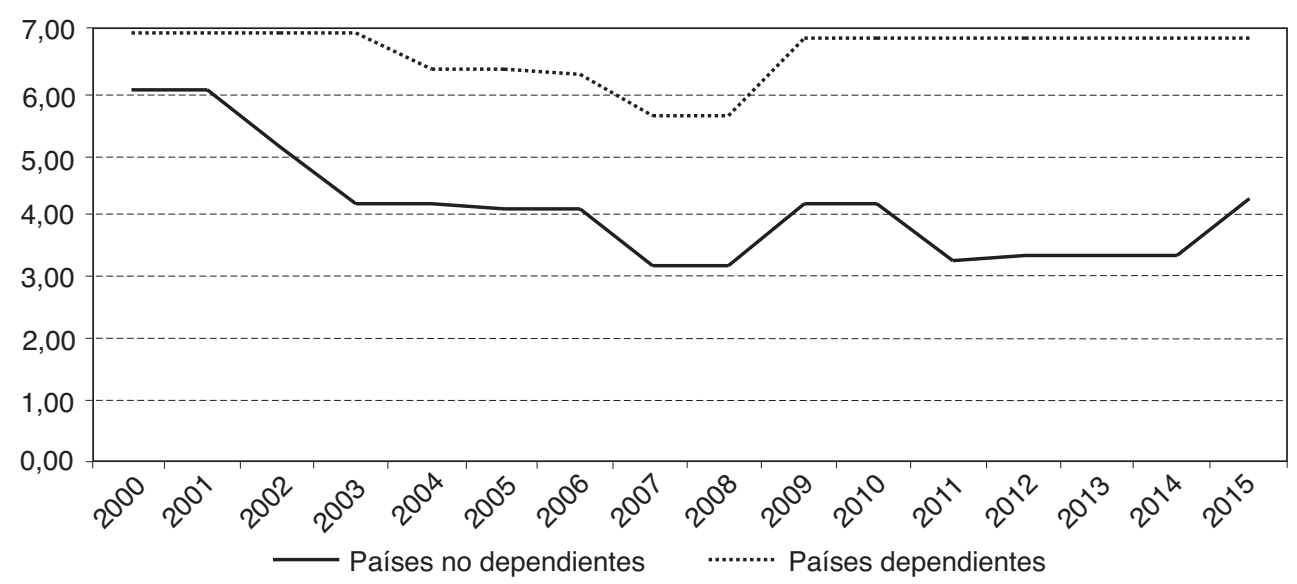

FUENTE: OCDE, Banco Mundial y elaboración propia.

\section{GRÁFICO 10}

CLASIFICACIÓN OCDE RIESGO-PAÍS: PAÍSES MENA. PAÍSES DEPENDIENTES Y NO DEPENDIENTES ENERGÉTICAMENTE

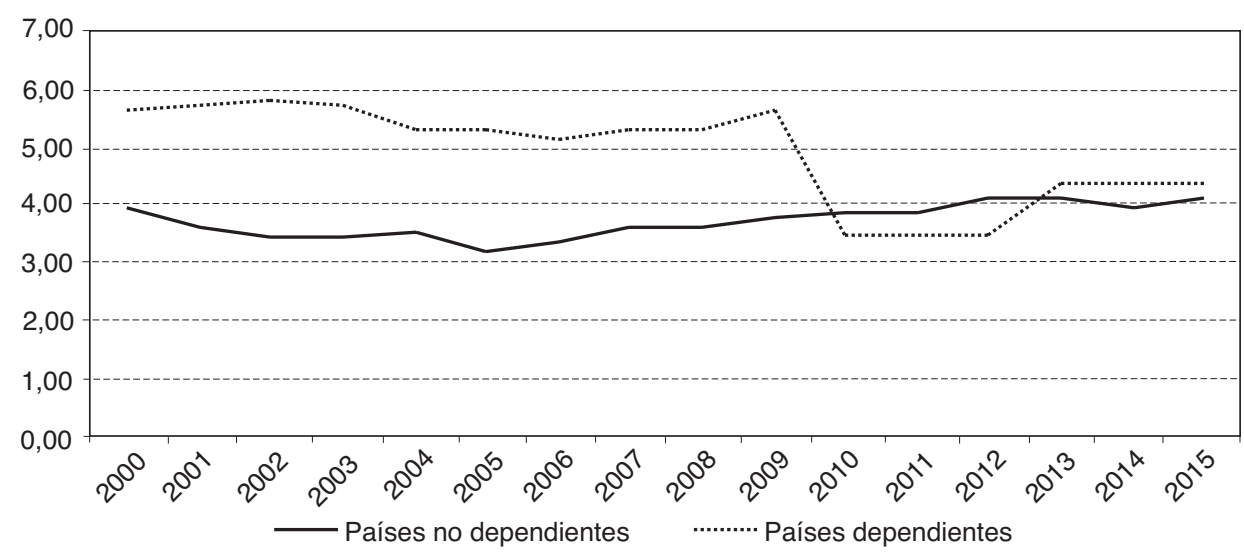

FUENTE: OCDE, Banco Mundial y elaboración propia. 


\section{GRÁFICO 11}

CLASIFICACIÓN OCDE RIESGO-PAÍS: PAÍSES AVANZADOS. PAÍSES DEPENDIENTES Y NO DEPENDIENTES ENERGÉTICAMENTE

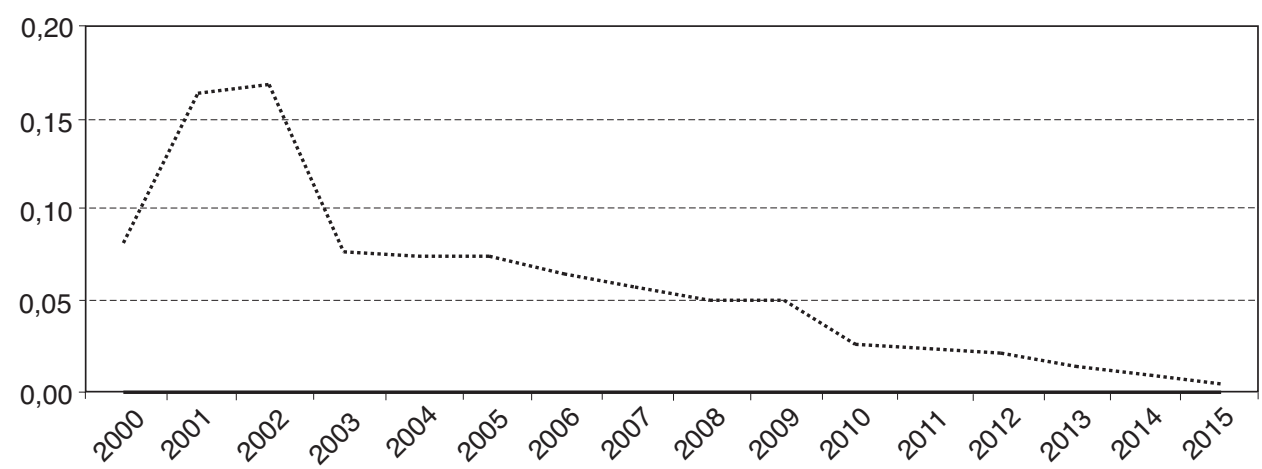

FUENTE: OCDE, Banco Mundial y elaboración propia.

\subsection{Calificaciones de riesgo soberano de las agencias de rating}

En África subsahariana (excepto 2001 y 2002), Asia emergente, países CEI, países avanzados y países MENA, las calificaciones de riesgo soberano de los países no dependientes son mejores que las de los dependientes. Las diferencias a favor de los países no dependientes respecto de la media de cada región son, respectivamente, del 26,6 por $100,23,5$ por $100,36,2$ por $100,7,24$ por 100 y 46 por 100 , en promedio del periodo observado.

En Latinoamérica, al igual que se ha observado con la clasificación de riesgo de la OCDE, sucede lo opuesto: los no dependientes se encuentran peor calificados que los dependientes a lo largo de todo el periodo analizado. La diferencia a favor de los países dependientes respecto de la media de la región es el 7,6 por 100.

Los Gráficos 12 a 17 muestran lo comentado. 


\section{GRÁFICO 12}

RATINGS SOBERANOS DE AGENCIAS: ÁFRICA SUBSAHARIANA.

PAÍSES DEPENDIENTES Y NO DEPENDIENTES

ENERGÉTICAMENTE

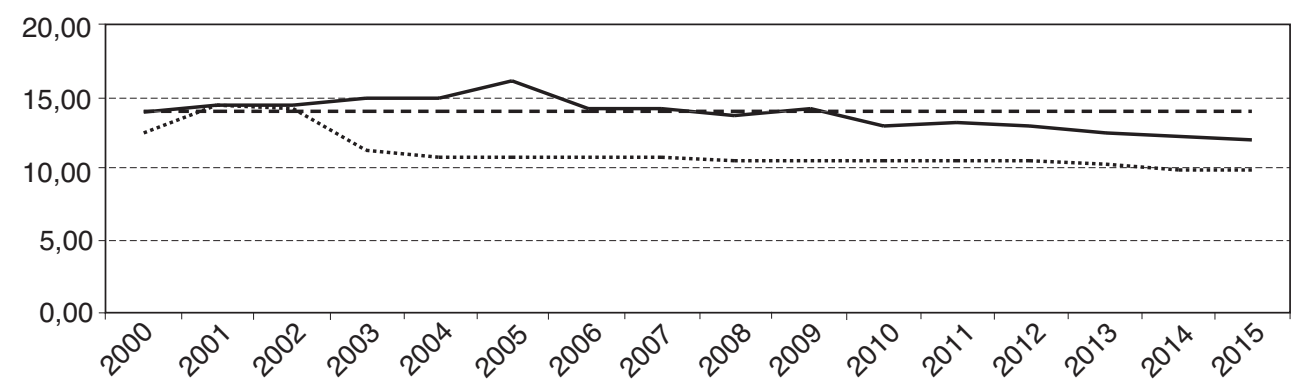

FUENTE: Moody's, Standard \& Poor's, Fitch, Banco Mundial y elaboración propia.

\section{GRÁFICO 13}

RATINGS SOBERANOS DE AGENCIAS: ASIA EMERGENTE

Y EN DESARAROLLO. PAÍSES DEPENDIENTES Y NO DEPENDIENTES ENERGÉTICAMENTE

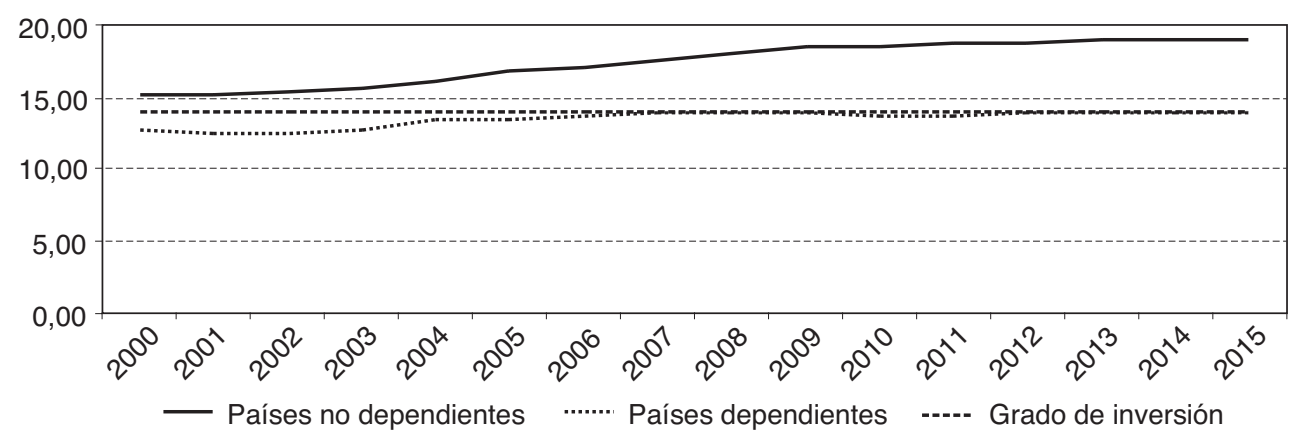

FUENTE: Moody's, Standard \& Poor's, Fitch, Banco Mundial y elaboración propia. 


\section{GRÁFICO 14}

RATINGS SOBERANOS DE AGENCIAS: LATINOAMÉRICA Y CARIBE. PAÍSES DEPENDIENTES Y NO DEPENDIENTES

\section{ENERGÉTICAMENTE}

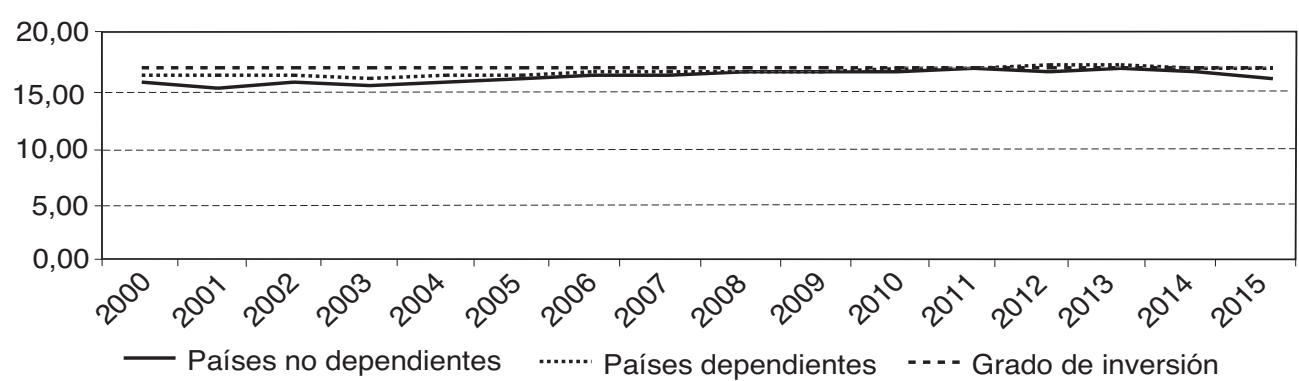

FUENTE: Moody's, Standard \& Poor's, Fitch, Banco Mundial y elaboración propia.

GRÁFICO 15

RATINGS SOBERANOS DE AGENCIAS: PAÍSES CEI. PAÍSES DEPENDIENTES Y NO DEPENDIENTES ENERGÉTICAMENTE

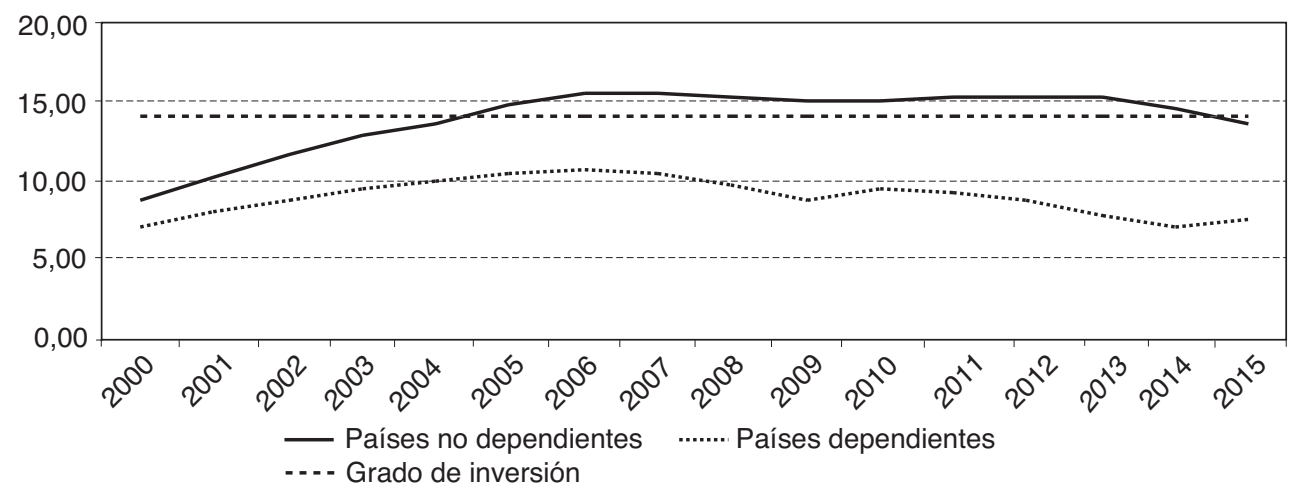

FUENTE: Moody's, Standard \& Poor's, Fitch, Banco Mundial y elaboración propia. 


\section{GRÁFICO 16}

RATINGS SOBERANOS DE AGENCIAS: PAÍSES MENA. PAÍSES

DEPENDIENTES Y NO DEPENDIENTES ENERGÉTICAMENTE

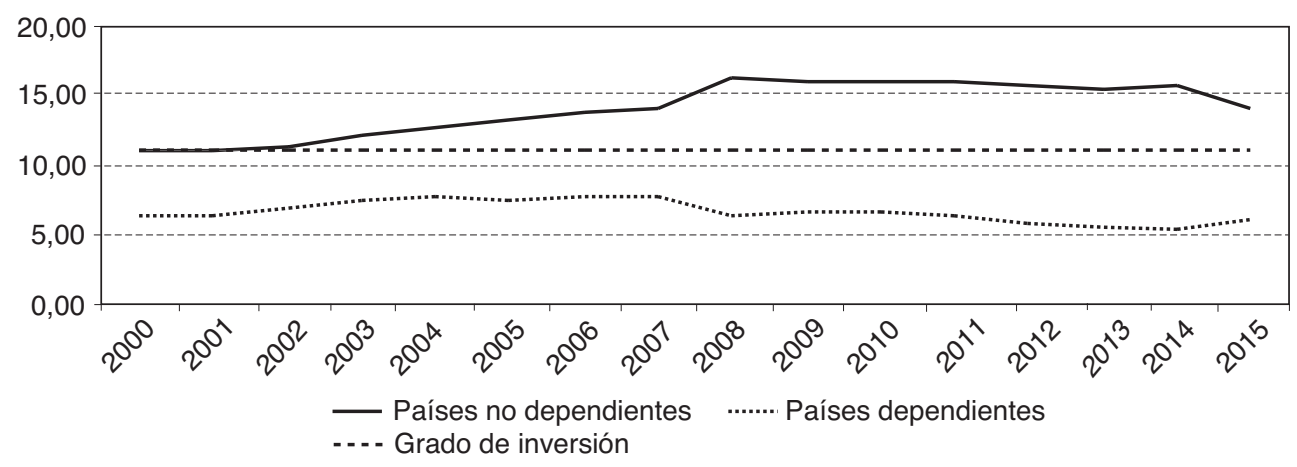

FUENTE: Moody's, Standard \& Poor's, Fitch, Banco Mundial y elaboración propia.

\section{GRÁFICO 17}

\section{RATINGS SOBERANOS DE AGENCIAS: PAÍSES AVANZADOS. PAÍSES DEPENDIENTES Y NO DEPENDIENTES ENERGÉTICAMENTE}

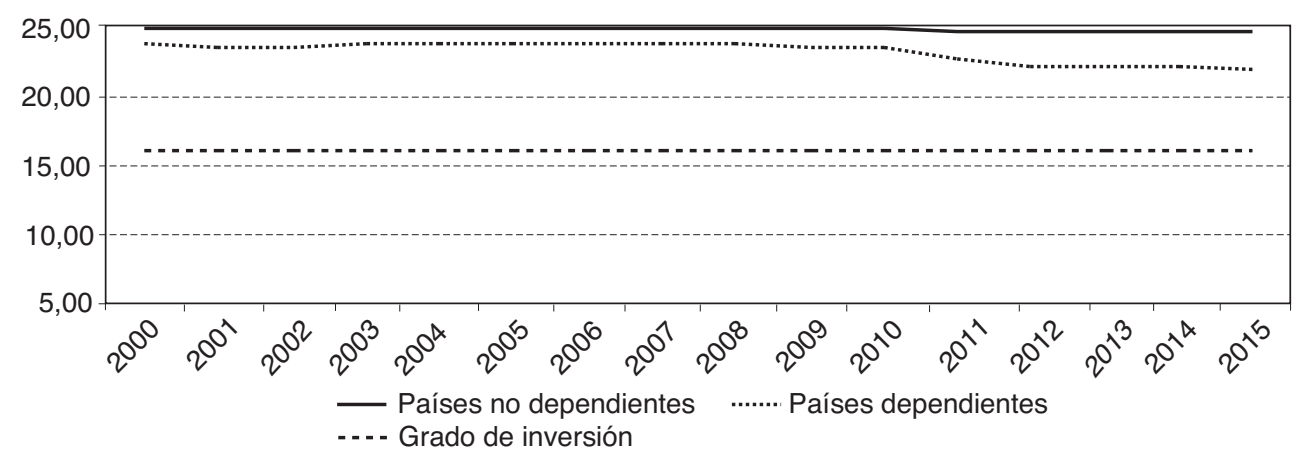

FUENTE: Moody's, Standard \& Poor's, Fitch, Banco Mundial y elaboración propia.

El Cuadro 2 muestra los principales resultados de la observación de los indicadores de riesgo-país en las distintas regiones y países del mundo, en función de su consideración como dependientes o no dependientes energéticamente.

Se cumple lo que en principio cabía esperar, y es que en promedio, a nivel regional, los países no dependientes energéticamente obtienen mejores calificaciones de riesgo-país, salvo en Latinoamérica. 


\section{CUADRO 2 \\ INDICADORES DE RIESGO-PAÍS Y PAÍSES DEPENDIENTES Y NO DEPENDIENTES ENERGÉTICAMENTE}

\begin{tabular}{|c|c|c|c|}
\hline & & Clasificación OCDE & Rating soberano \\
\hline \multirow{2}{*}{ África subsahariana } & Dependientes & & \\
\hline & No dependientes & $\mathrm{X}$ & $\begin{array}{c}\mathrm{X} \\
\text { (Excepto 2001-2002) }\end{array}$ \\
\hline \multirow{2}{*}{ Latinoamérica y Caribe } & Dependientes & $\begin{array}{c}\mathrm{X} \\
\text { (Excepto 2004-2008) }\end{array}$ & $\mathrm{X}$ \\
\hline & No dependientes & & \\
\hline \multirow{2}{*}{ Asia emergente y en desarrollo } & Dependientes & & \\
\hline & No dependientes & $\mathrm{X}$ & $X$ \\
\hline \multirow{2}{*}{ Países CEI } & Dependientes & & \\
\hline & No dependientes & $\mathrm{X}$ & $X$ \\
\hline \multirow[b]{2}{*}{ Países MENA } & Dependientes & & \\
\hline & No dependientes & $\begin{array}{c}\mathrm{X} \\
\text { (Excepto 2010-2013)) }\end{array}$ & $\mathrm{X}$ \\
\hline \multirow{2}{*}{ Países avanzados } & Dependientes & & \\
\hline & No dependientes & $\mathrm{X}$ & $\mathrm{X}$ \\
\hline
\end{tabular}

FUENTE: OCDE, JP Morgan, Moody's, Standard \& Poor's, Fitch, Banco Mundial y elaboración propia.

NOTA: La cruz señala la categoría (dependiente o no dependiente) en la que el indicador de riesgo-país es más favorable.

Precisamente, en esa región el indicador de gobernanza WGI muestra que los países Dependientes energéticamente se encuentran en promedio mejor gobernados que los países con recursos energéticos abundantes (Worldwide Governance Indicators, World Bank, informes 2000 a 2014). Además, en Latinoamérica, a diferencia de las demás regiones, se obtienen calificaciones de signo contrario en no dependientes y en dependientes empleando los valores originales del WGI, para los que se observan valores negativos en los no dependientes y positivos en los dependientes, y ello a lo largo de todo el periodo considerado. Esta no es la única región para la que el indicador WGI es más favorable en los países dependientes que en los no dependientes energéticamente, ya que también Asia muestra este comportamiento. Sin embargo, en Latinoamérica la diferencia a favor de los dependientes (21 por 100) es mucho mayor que en Asia (9 por 100). Parece claro que la peor calidad de la gobernanza de los países latinoamericanos no dependientes energéticamente estaría impactando negativamente en sus indicadores de riesgo-país. 
El análisis que se acaba de realizar ha permitido apreciar la existencia de comportamientos diferenciales entre las distintas regiones en cuanto a la relación entre riesgo-país y la dependencia y no dependencia energética. Sin embargo, el estudio tiene un carácter estático, por cuanto no permite ver dentro de cada región y subgrupo cuál es la evolución de la dependencia energética a lo largo del periodo, ni por tanto establecer relaciones de causalidad entre dicha dependencia y los niveles de riesgo-país. Ese es precisamente el objeto del siguiente apartado.

\section{El riesgo-país y la dependencia energética: resultados econométricos}

En el presente apartado se ha buscado una relación de causalidad entre los indicadores representativos del riesgo-país y de la dependencia energética, mediante la realización de regresiones lineales, en las que se busca explicar la variable dependiente «y» de riesgo-país medio (ponderado por el PIB de cada país, según los datos del Banco Mundial ya comentados) a través de la variable independiente « $\mathrm{X}$ » de dependencia energética media (también ponderada por el PIB). La robustez de las estimaciones ha sido probada a través de diversos tests, que han arrojado resultados satisfactorios en 10 de un total de 14 regresiones.

No es posible comparar directamente los resultados del epígrafe anterior con los del presente apartado sobre resultados econométricos, porque el estudio es esencialmente distinto en uno y otro caso. En el epígrafe anterior los datos de riesgo-país han sido observados a lo largo del periodo analizado siguiendo un orden cronológico, y comparando las medias entre los grupos de países dependientes e independientes. En el presente epígrafe se trata de estudiar la relación estadística entre series temporales de riesgo-país y dependencia energética.

Las regresiones a lo largo del tiempo en las distintas regiones arrojan resultados interesantes, que muestran grados de correlación suficientemente significativos en la mayoría de los casos.

En el caso de los datos de dependencia energética, las medias ponderadas se han realizado empleando los países incluidos en la clasificación de riesgo-país de la OCDE, indicador que ofrece un número muy amplio de países. El periodo cubierto es 2000-2014, ya que no se dispone de series más largas.

Se ha trabajado con los indicadores clasificación de riesgo-país de la OCDE, calificaciones de riesgo soberano de las agencias de rating y EMBI Global. Sin embargo, los resultados obtenidos con este último indicador no son satisfactorios, debido a que, como ya se ha señalado, existe un número de observaciones excesivamente bajo.

El Gráfico 18 muestra la evolución del indicador de dependencia energética del Banco Mundial de todas las regiones del mundo. Este indicador se define como:

$$
\frac{C-P}{C} \times 100
$$

donde $C$ es el consumo de energías fósiles y $P$ su producción. 


\section{GRÁFICO 18 \\ DEPENDENCIA ENERGÉTICA 2000-2014}

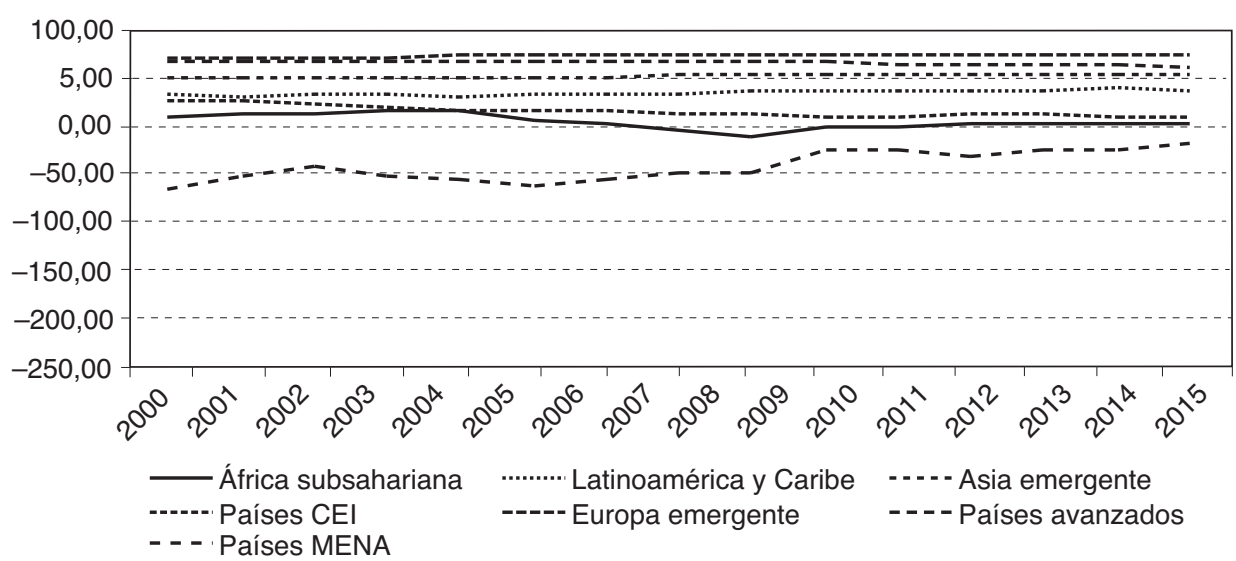

FUENTE: Banco Mundial y elaboración propia.

Valores negativos indican que la región es en promedio exportadora neta de recursos energéticos (la producción supera el consumo). En el tramo negativo el indicador puede alcanzar cualquier valor. En el tramo positivo del indicador (que significa que el consumo supera la producción y, por tanto, el país es importador neto de recursos energéticos), el máximo valor que puede alcanzar es 100, que refleja que la región debe importar el 100 por 100 de los recursos energéticos que consume.

Como cabía esperar, la región más exportadora, a gran distancia de las demás, es la de los países MENA, que en promedio exporta entre el 234 por 100 y el 138 por 100 de su consumo energético a lo largo del periodo. La región más importadora es Europa Emergente, que importa entre el 43 por 100 y el 49 por 100 de su consumo energético durante el periodo. Los países desarrollados oscilan entre un 22 por 100 y un 24 por 100 de importación en promedio. Lógicamente el peso de Estados Unidos en el dato de los países avanzados es significativo, al tratarse de una media ponderada por PIB. Asia emergente se encuentra en valores cercanos a la autosuficiencia energética, si bien con una leve tendencia hacia el incremento de la importación de energía. En esa región el peso de China determina buena parte de la evolución descrita.

La metodología seguida en el análisis econométrico ha consistido en efectuar regresiones lineales entre la variable independiente «Dependencia energética» y el «Riesgo país» como variable dependiente, midiendo el riesgo a partir de los dos indicadores alternativos, la clasificación de riesgo-país de la OCDE y las calificaciones de riesgo soberano de las agencias de calificación (rating).

El indicador de dependencia energética ofrecido por el Banco Mundial (IBM) ha sido objeto de conversión a valores positivos, evitando así que signos positivos y negativos en un mismo país a lo largo del tiempo interfieran en los resultados de la regresión. El indicador en valor positivo se ha definido como $P / C$ (producción 
dividido por consumo de energías fósiles). Despejando este factor de la expresión

$$
\mathrm{IBM}=\frac{C-P}{C} \times 100
$$

se obtiene que $P / C=100-$ IBM.

Las regresiones lineales (catorce en total, al haberse considerado siete zonas regionales) han sido sometidas a un test global de verificación de los supuestos del modelo lineal de regresión mínimo-cuadrática, concretamente a un test de «GVLM» («Global Valuation of Linear Model Assumptions»). Este ha consistido en verificar el cumplimiento de los supuestos estándares sobre asimetría («skewness»), curtosis, homoscedasticidad y relación de linealidad, principalmente (Peña y Slate, 2006). Para corregir problemas de posible autocorrelación y/o heteroscedasticidad en el modelo, se han estimado los errores estándares de los parámetros de la regresión con el método de Newey-West (Newey y West, 1987).

Los gráficos de las regresiones realizadas para los indicadores de clasificación de riesgo-país de la OCDE y de ratings soberanos de agencias se ofrecen a continuación.

a) Gráficos de regresión clasificación de riesgo-país de la OCDE y dependencia energética:

\section{GRÁFICO 19}

\section{CLASIFICACIÓN OCDE Y DEPENDENCIA ENERGÉTICA.}

\section{LATINOAMÉRICA Y CARIBE}

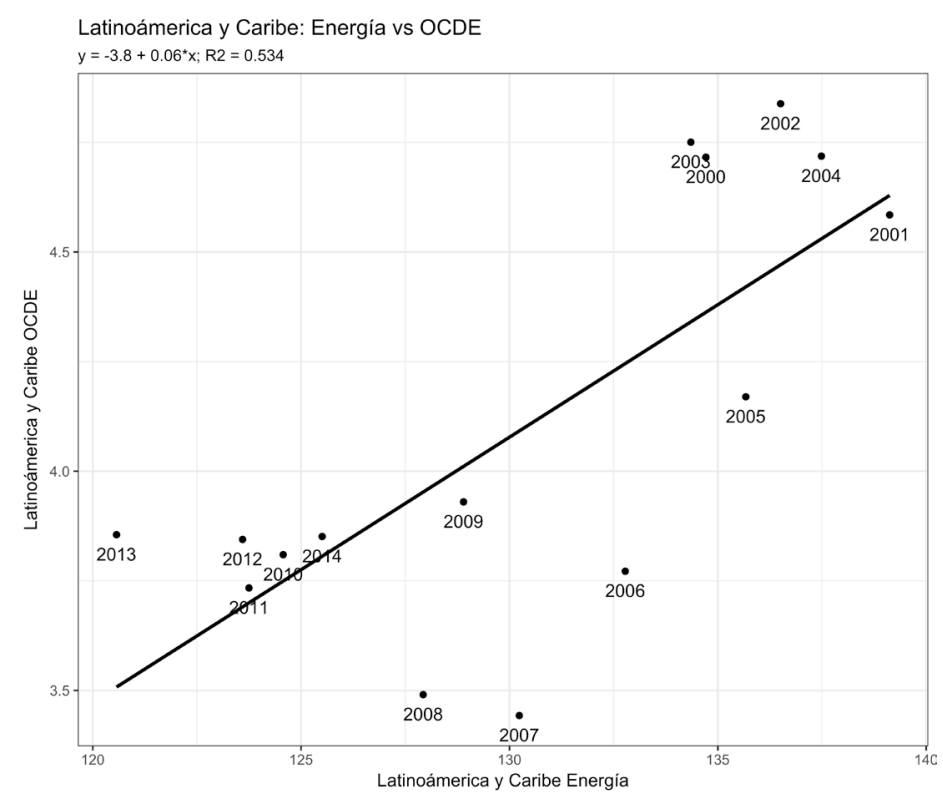




\section{GRÁFICO 20}

CLASIFICACIÓN OCDE Y DEPENDENCIA ENERGÉTICA. ASIA EMERGENTE Y EN DESARROLLO

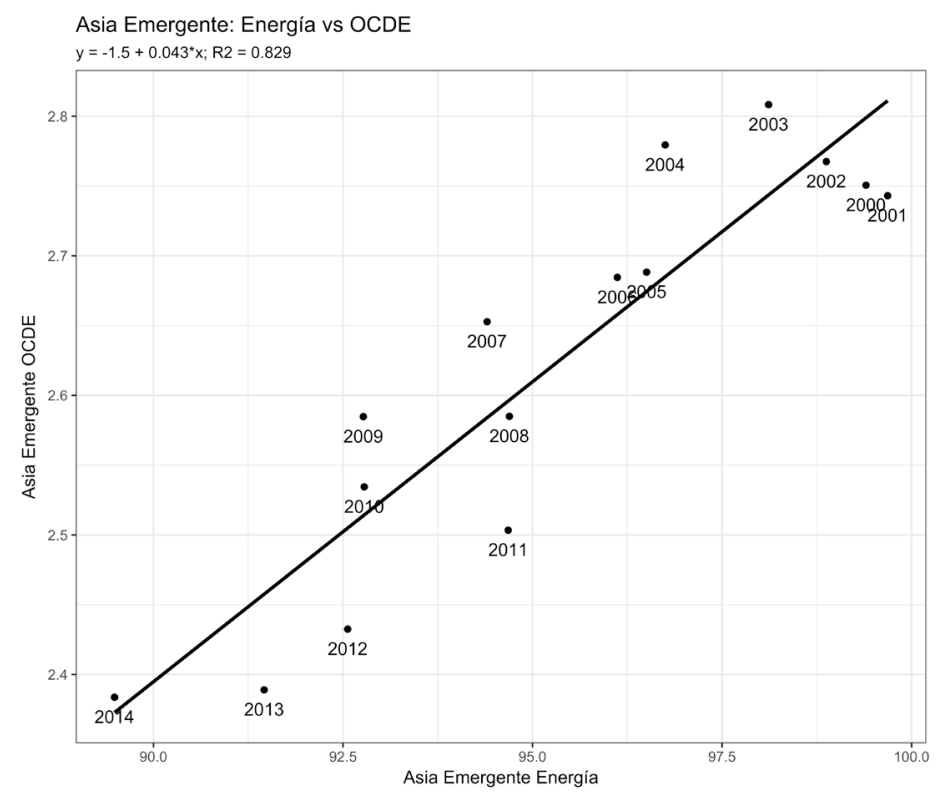

GRÁFICO 21

CLASIFICACIÓN OCDE Y DEPENDENCIA ENERGÉTICA. PAÍSES CEI

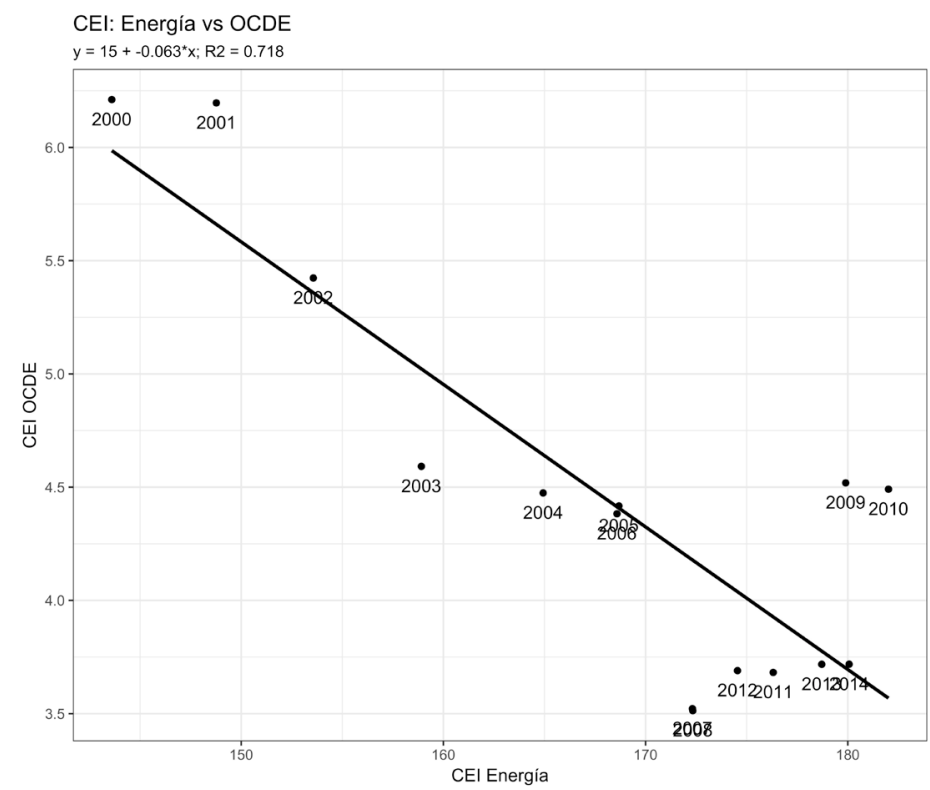




\section{GRÁFICO 22}

CLASIFICACIÓN OCDE Y DEPENDENCIA ENERGÉTICA. EUROPA EMERGENTE Y EN DESARROLLO

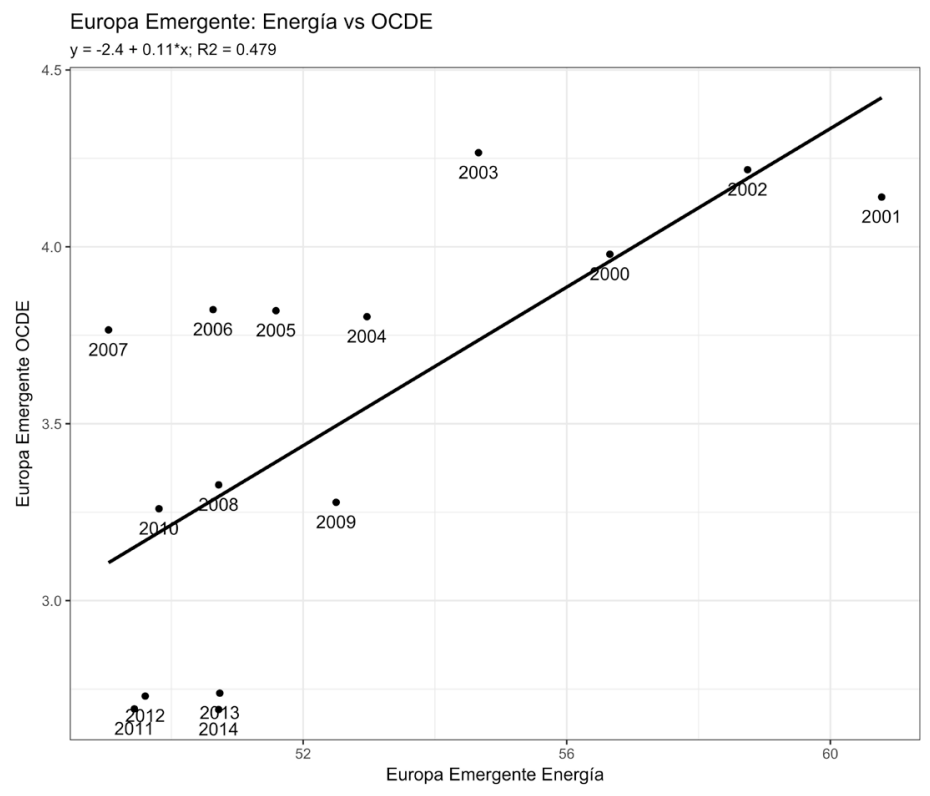

GRÁFICO 23

CLASIFICACIÓN OCDE Y DEPENDENCIA ENERGÉTICA. PAÍSES AVANZADOS

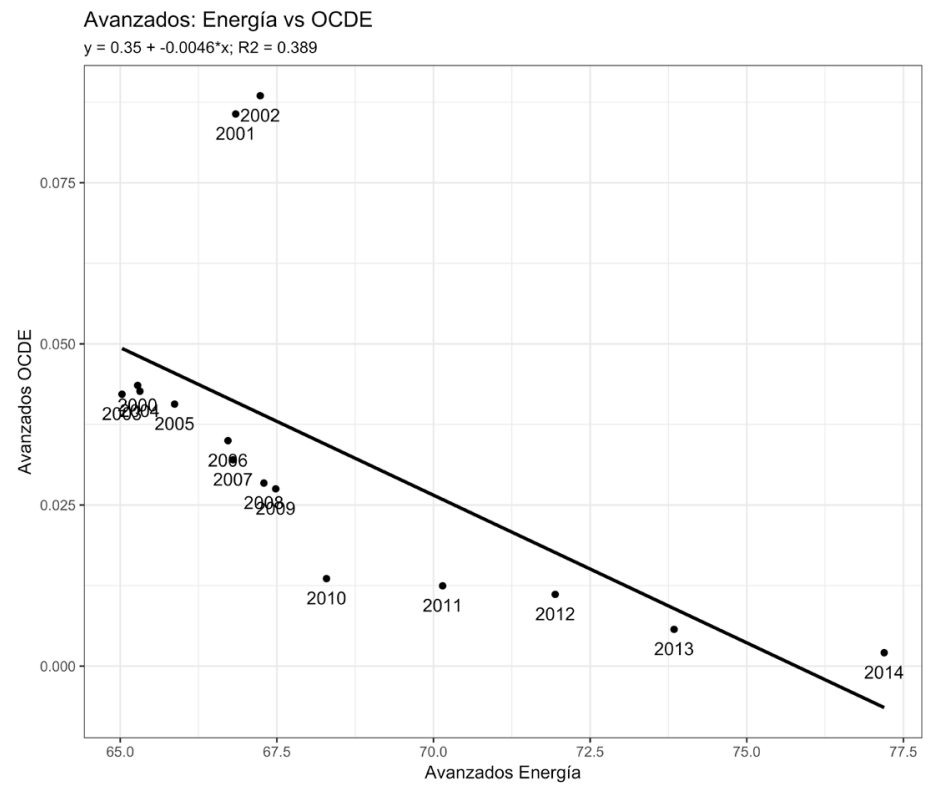




\section{GRÁFICO 24}

\section{CLASIFICACIÓN OCDE Y DEPENDENCIA ENERGÉTICA. PAÍSES MENA}

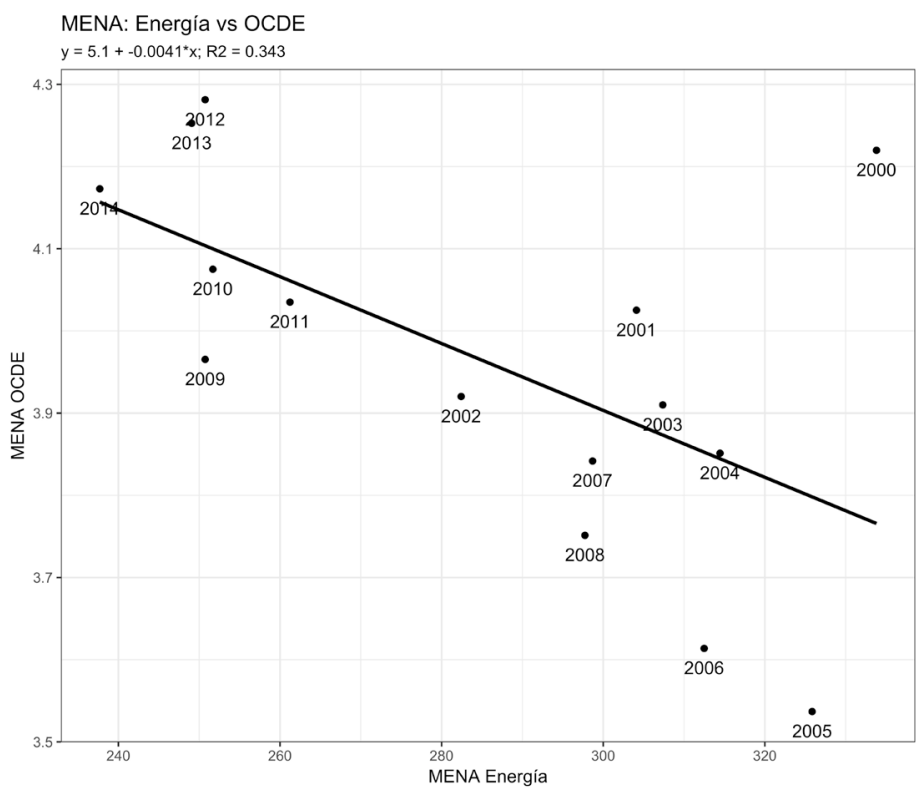

b) Gráficos de regresión de ratings soberanos de agencias y dependencia energética:

\section{GRÁFICO 25}

\section{RATINGS SOBERANOS Y DEPENDENCIA ENERGÉTICA. \\ LATINOAMÉRICA Y CARIBE}

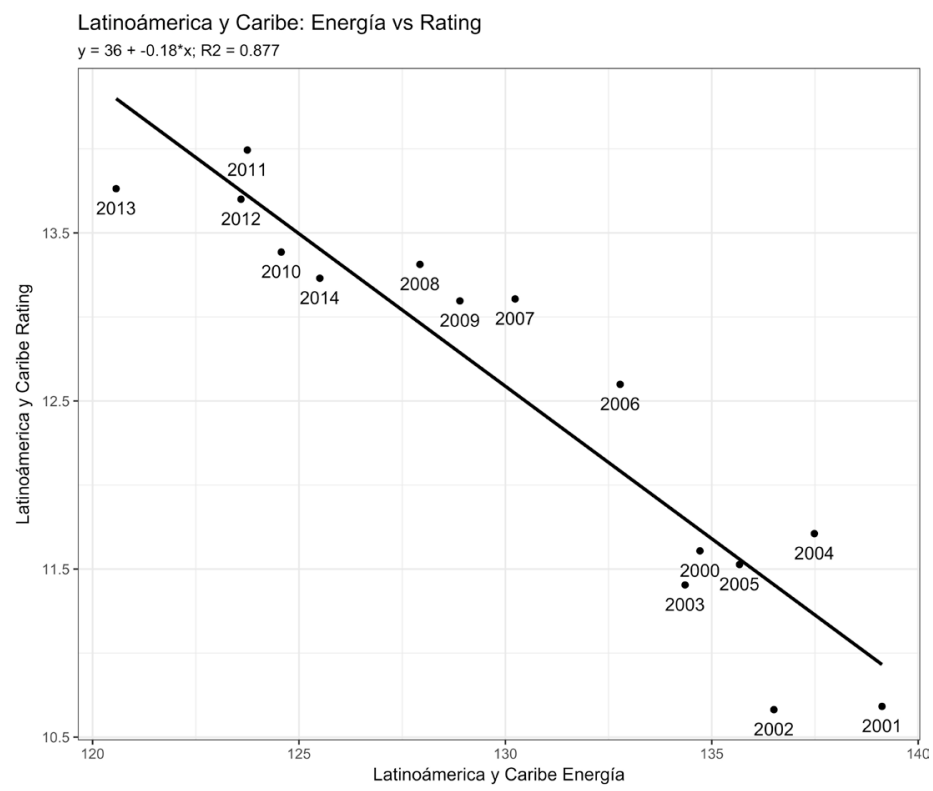




\section{GRÁFICO 26}

RATINGS SOBERANOS Y DEPENDENCIA ENERGÉTICA. ASIA EMERGENTE Y EN DESARROLLO

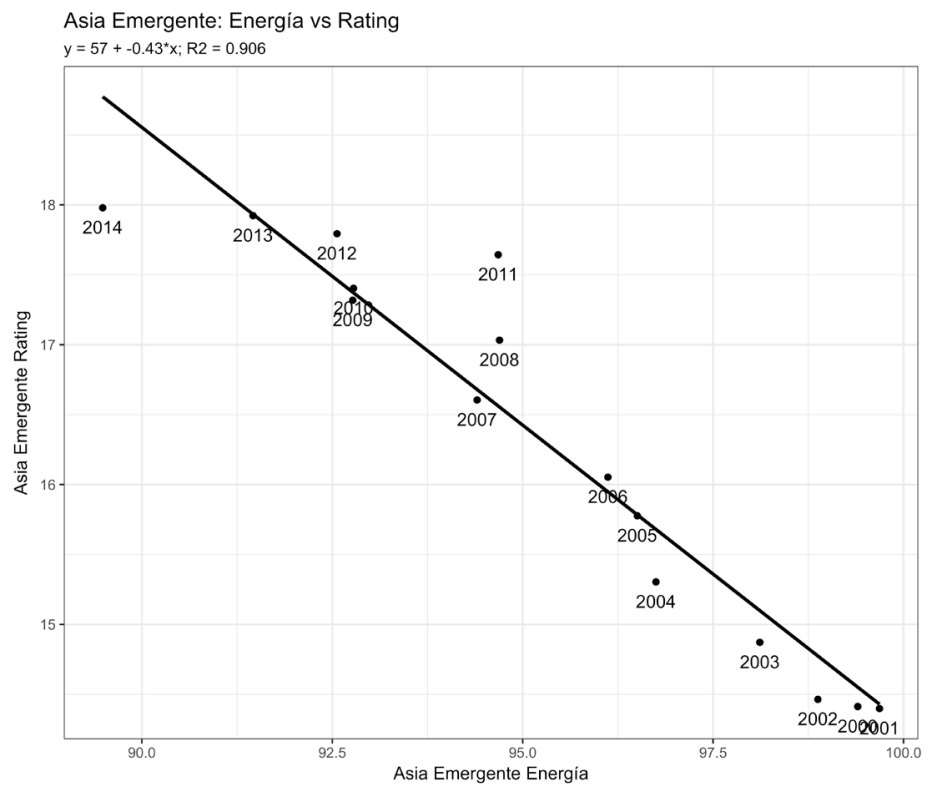

GRÁFICO 27

RATINGS SOBERANOS Y DEPENDENCIA ENERGÉTICA.

\section{PAÍSES CEI}

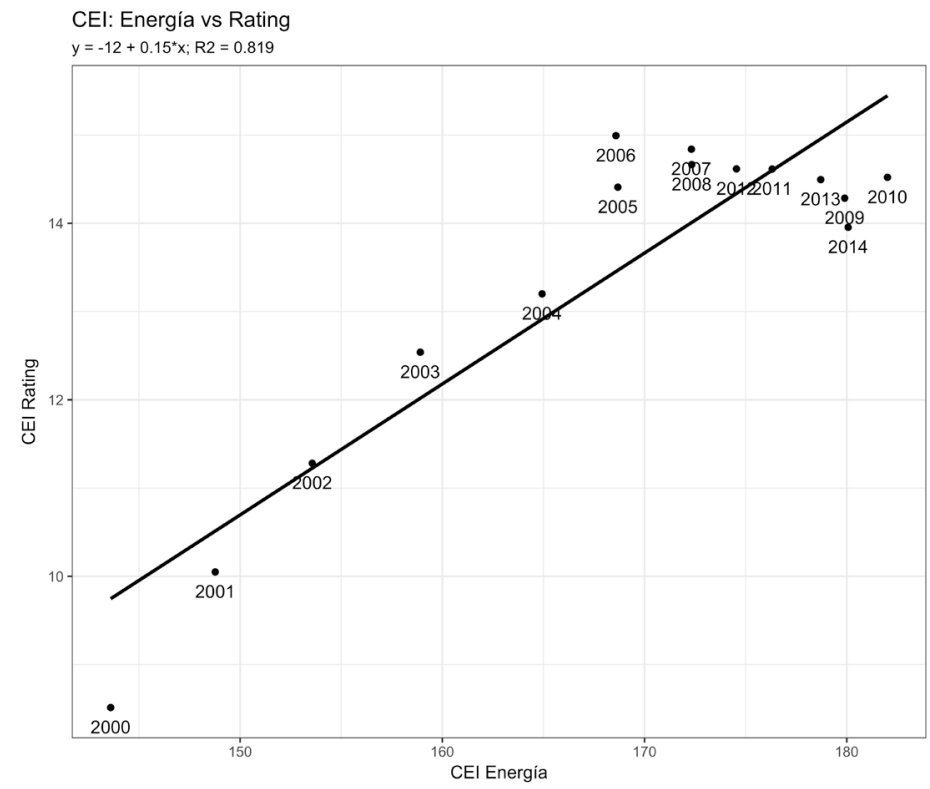




\section{GRÁFICO 28 \\ RATINGS SOBERANOS Y DEPENDENCIA ENERGÉTICA. EUROPA EMERGENTE}

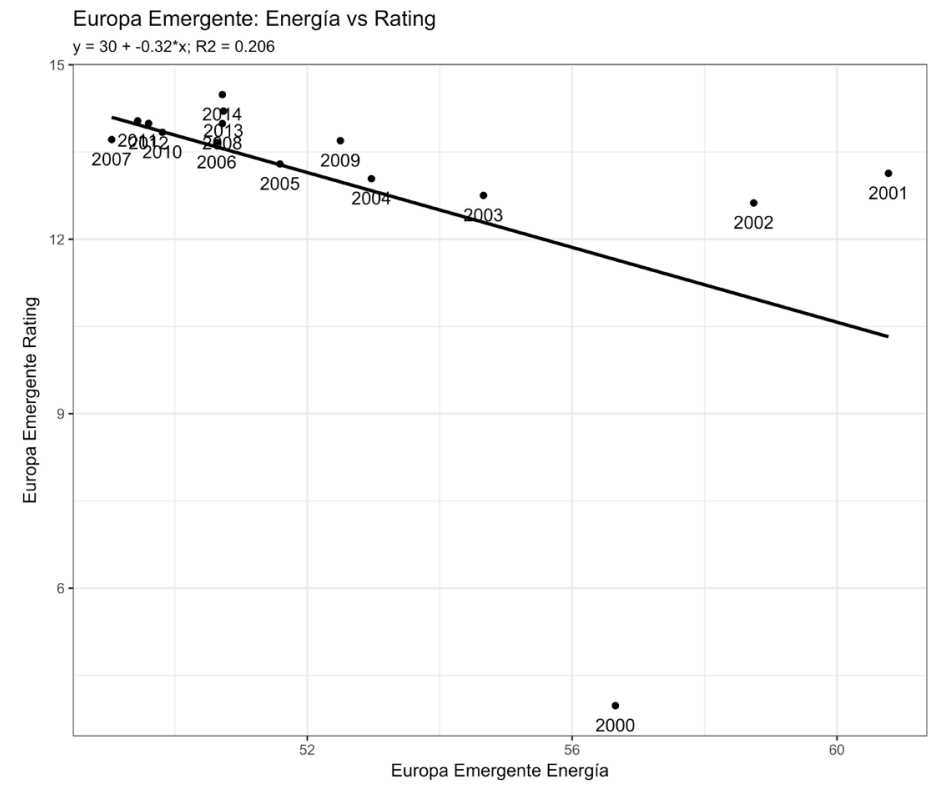

\section{GRÁFICO 29 \\ RATINGS SOBERANOS \\ Y DEPENDENCIA ENERGÉTICA. PAÍSES AVANZADOS}

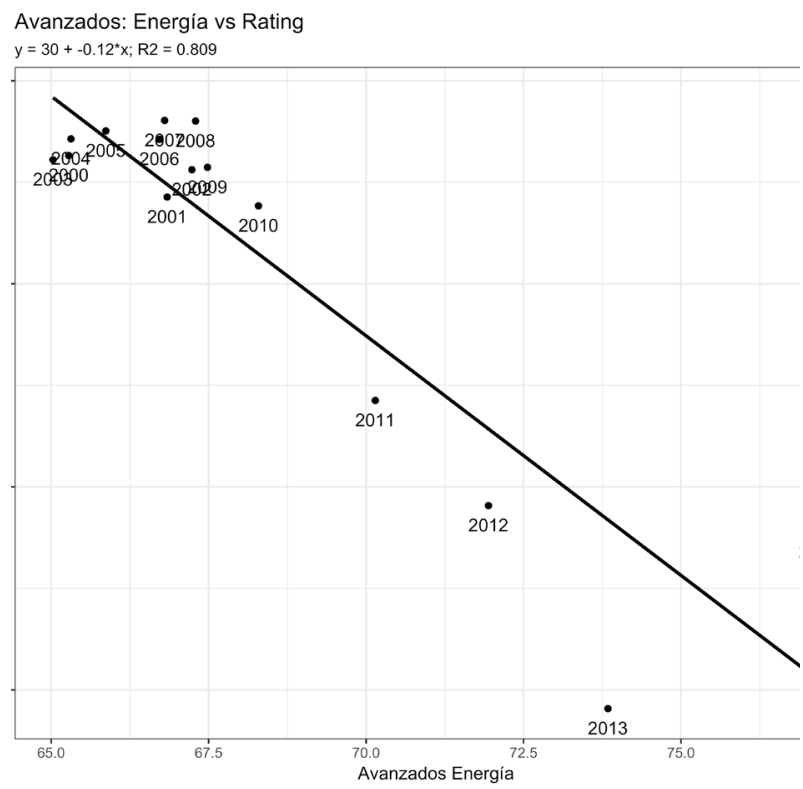




\section{GRÁFICO 30 \\ RATINGS SOBERANOS Y DEPENDENCIA ENERGÉTICA. PAÍSES MENA}

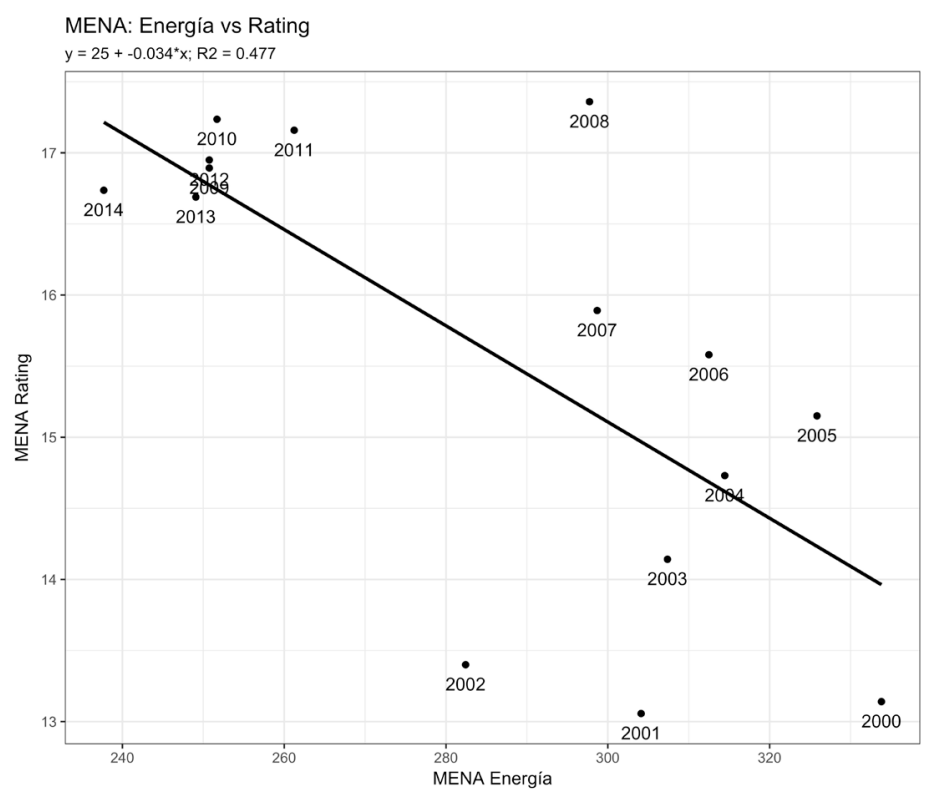

c) Cuadro de resultados de las regresiones en el tiempo 2000-2014, dependencia energética y riesgo-país

En el Cuadro 3 se muestran los valores de la constante, el regresor de la variable independiente, el $\mathrm{R}^{2}$, las probabilidades («p-values») de los estimadores NeweySeWest, así como el grado de robustez de las regresiones.

Las regresiones realizadas merecen los siguientes comentarios:

Se aprecia un impacto positivo y significativo entre la dependencia energética y el riesgo país, medido tanto a través de la clasificación de riesgo-país de la OCDE como a través de las calificaciones de riesgo soberano de las tres principales agencias, con las únicas excepciones de África subsahariana para los dos indicadores de riesgo-país, y de Europa emergente en el caso de los dos indicadores de riesgo-país. Es decir, los resultados son significativos y robustos en 10 de las 14 regresiones realizadas.

En el caso de las calificaciones de riesgo soberano (rating soberano), su comportamiento ante variaciones de la dependencia energética muestra una importante regularidad en las distintas regiones: en todas ellas, cuando mejora la dependencia energética (esto es, la región incrementa su autosuficiencia energética o sus exportaciones), empeora el riesgo-país. La única excepción es la región CEI, en la que cuando se reduce la dependencia del exterior, mejora el riesgo-país. En los casos de Latinoamérica, Asia emergente, países CEI y países avanzados, el grado de corre- 


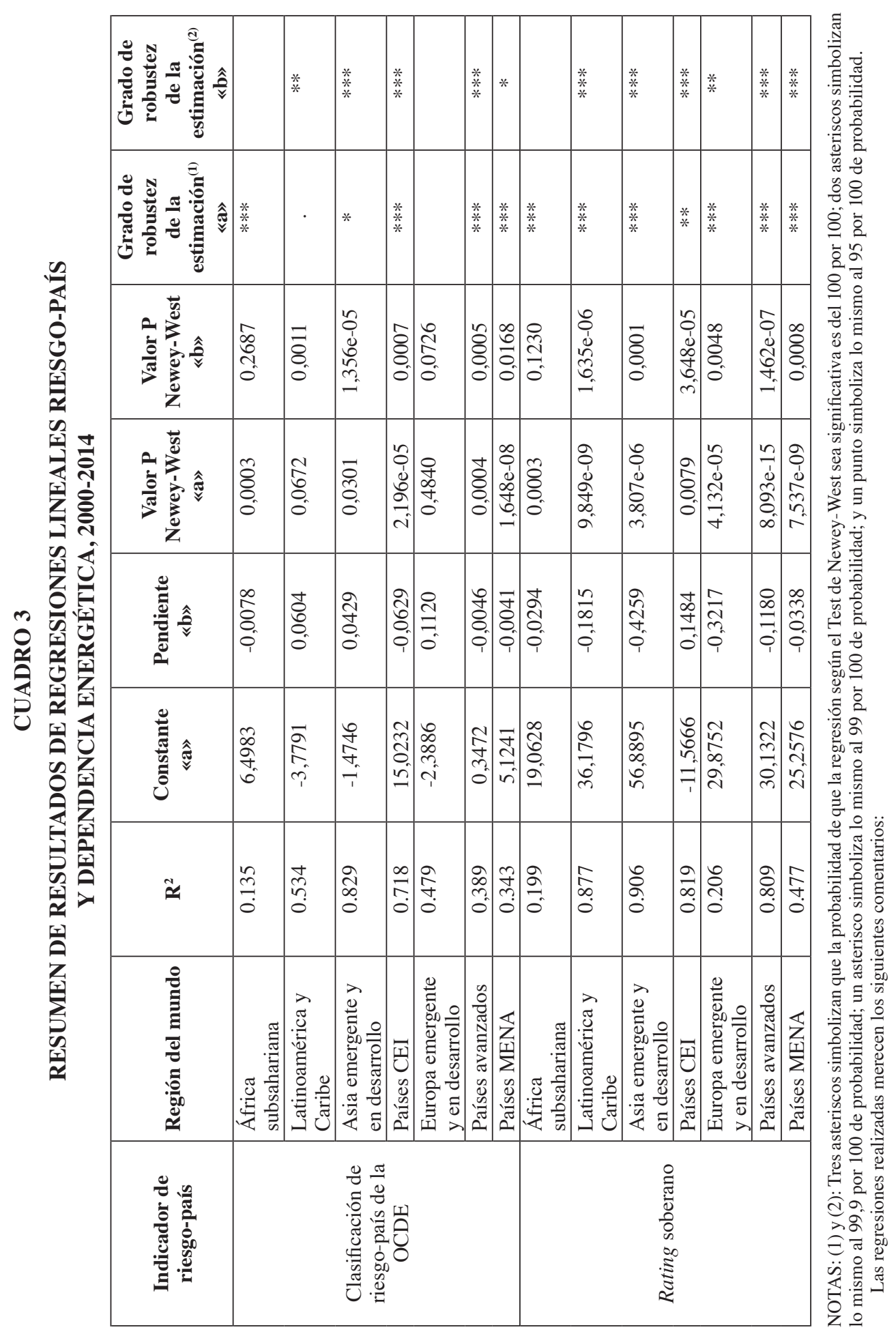


lación es elevado, con un poder explicativo de la variable independiente de entre el 80 por 100 y el 91 por 100 . En el caso de MENA es el 47,7 por $100 \mathrm{y}$ en el caso de Europa emergente es el 20,6 por 100.

En el caso de la clasificación de riesgo-país de la OCDE, el comportamiento del riesgo-país ante variaciones de la dependencia energética es menos homogéneo entre regiones: en Latinoamérica y Asia emergente, el riesgo-país empeora cuando se reduce la dependencia energética (pendiente positiva de la recta de regresión), en línea con lo observado en el caso de los ratings soberanos. El grado explicativo de la variable independiente (dependencia energética) sobre la variable dependiente (riesgo-país) es del 53 por 100 en Latinoamérica y del 82,9 por 100 en Asia Emergente. En los países CEI, avanzados y MENA se aprecia el comportamiento inverso: una mejora del riesgo-país conforme aumenta la autosuficiencia energética o las exportaciones de recursos energéticos (pendiente negativa de la recta de regresión). El grado explicativo de la variable independiente es del 71,8 por 100 en los países CEI. En los países avanzados y MENA, el poder explicativo es menor, 38,9 por 100 y 34 por 100, respectivamente, y desde luego mucho menor que en el caso de los ratings soberanos en esas dos regiones, como se ha visto.

En los dos indicadores de riesgo-país (clasificación de riesgo-país de la OCDE y calificaciones de riesgo soberano), el diferente comportamiento de las variables estudiadas entre la región de CEI, por un lado, y Latinoamérica y Asia emergente, por otro, en realidad no es tal a lo largo de todo el periodo 2000-2014, ya que en CEI se observan dos comportamientos distintos en la primera y en la segunda mitad del periodo analizado. En la etapa 2000-2005, la región CEI se comporta de manera distinta a Latinoamérica y Asia emergente, mientras que durante la segunda, 20062014, el comportamiento es similar. La explicación sobre el comportamiento diferencial entre los años 2000 y 2005 reside, en opinión de la autora, en que, por un lado, Rusia pesa de manera significativa en la región CEI, al representar el 70 por 100 del PIB de la región (y por tanto explica la mayor parte del comportamiento de los indicadores de riesgo-país y de dependencia energética). Por otro lado, es un hecho que en los primeros años del periodo analizado (2000-2005) se produjo la recuperación de la crisis financiera de Rusia de finales de los años 90 (sufrida por contagio de la crisis asiática), gracias a la reestructuración de su deuda externa en el Club de París y la ayuda financiera del Fondo Monetario Internacional, lo que permitió una mejora acelerada de las calificaciones soberanas de la deuda y de la clasificación de la OCDE en los primeros años de la década de los 2000, desde niveles muy bajos. En efecto, entre 2000 y 2005, el rating soberano medio de Rusia de las tres agencias subió siete escalones, desde B- hasta BBB, y la clasificación de riesgo-país de la OCDE pasó de 7 a 4. Tras esa recuperación, y a partir de 2005-2006, se observa en los gráficos 21 y 27 que la evolución de los referidos indicadores fue a la baja: entre 2006 y 2014 el rating soberano se redujo hasta BB, y la clasificación de la OCDE osciló entre 3 y 4, provocando que la región se comportase de manera similar a Latinoamérica y Asia emergente (relación inversa entre dependencia energética e indicadores de riesgo-país). 
En cuanto a las regiones de MENA y avanzados, parece claro que las regresiones realizadas con los ratings soberanos muestran una capacidad explicativa sustancialmente mayor que en el caso de las clasificaciones de riesgo-país de la OCDE (véase Cuadro 3), por lo parece más adecuado elegir las primeras frente a las segundas. En el caso de los países MENA, adicionalmente, el grado de robustez de la regresión con el rating soberano es mucho más fuerte.

La diferencia en la pendiente de la línea de regresión de MENA en los dos indicadores de riesgo-país se debe a unas calificaciones divergentes entre la OCDE y las agencias de rating acerca del riesgo-país de la región: en el caso de la OCDE, el riesgo-país de MENA es mayor en el periodo 2008-2014 que en el periodo 2000-2007. Para las agencias de rating ocurre lo contrario, debido probablemente a los elevados precios internacionales de las energías fósiles entre 2008-2014, que incrementaron notablemente el PIB de estos países.

Por último, las regresiones correspondientes a la región de Europa emergente, tanto en el caso de la clasificación de riesgo-país de la OCDE como en el caso de los ratings soberanos, no van a ser objeto de consideración. En el caso de la clasificación de riesgo-país de la OCDE, la estimación carece de robustez (véase Cuadro 3), y en el caso de los ratings soberanos, el poder explicativo de la regresión es solamente del 20,6 por 100 .

En conclusión, las regresiones realizadas, con los matices expresados en párrafos anteriores, muestran que la reducción de la dependencia energética conduce a un empeoramiento de los indicadores de riesgo-país, lo que apunta al refuerzo de las teorías sobre la «maldición de los recursos» a lo largo de todo el periodo considerado (véase una discusión sobre esta cuestión en Humphreys, Sachs y Stiglitz, 2007). Diversos autores (FMI, 2012; Venables, 2016) opinan que dicha «maldición» fue importante en la década de los noventa, pero no en la década siguiente, en que el crecimiento económico per cápita de los países poseedores de recursos naturales en promedio alcanzó un nivel semejante al de los países carentes de ellos.

El argumento tradicionalmente empleado para explicar la «maldición de los recursos naturales», o en este caso la «maldición de las energías fósiles», que parece detectarse en Latinoamérica y Asia emergente es la «enfermedad holandesa ${ }^{9}$, o en inglés Dutch disease. Sin embargo, existen otros factores que explican esta «maldición», como los que se citan a continuación, que se dan más en países emergentes y en desarrollo que en países avanzados (Iranzo, 2008):

${ }^{9}$ La enfermedad holandesa se refiere a los efectos negativos sobre la exportación e industrialización de un país derivados de la apreciación del tipo de cambio producida por un incremento sustancial de los ingresos en divisas de ese país. Ello conduce a la desindustrialización y a la dependencia de la producción y exportación de energías fósiles para la generación de PIB, empleo, ingresos tributarios y divisas extranjeras. La economía termina siendo un «monocultivo» de petróleo, generándose un sinfín de desequilibrios cuando sus precios descienden (déficit público, déficit exterior, desempleo, endeudamiento exterior y conflictos sociales y políticos), lo que lleva a un deterioro de los indicadores de riesgo-país, ante el aumento del riesgo de impago de la deuda externa. La expresión se remonta a los años 60 del siglo pasado, cuando las entradas de divisas en los Países Bajos se incrementaron significativamente por sus exportaciones de gas natural, descubierto cerca del Mar del Norte. 
- El sector de extracción de petróleo y gas es poco trabajo intensivo y genera poco valor añadido local, pues la tecnología y los bienes de equipo deben ser importados desde los países desarrollados, y los trabajadores de cualificación media o alta no siempre abundan en los países emergentes y en desarrollo. Por ello, el PIB no aumenta apreciablemente con el desarrollo del sector.

- Los ingresos por la venta del petróleo son altamente volátiles, dada la variabilidad de los precios del petróleo, lo que dificulta considerablemente la elaboración del presupuesto nacional. Además, los vaivenes en los ingresos públicos incentivan la alteración de las normas tributarias por parte de los gobiernos, lo que compromete la seguridad jurídica y desincentiva la inversión extranjera en el sector.

- Los países productores de petróleo y gas obtienen cuantiosos ingresos públicos por la exportación del petróleo. Por esta razón los gobiernos productores pueden prescindir en buena medida de la recaudación de impuestos. Ello hace que ni los gobiernos ni los electores que los votan se preocupen por una adecuada gestión de los ingresos públicos, que no le han costado esfuerzo al contribuyente. Ello permite conductas poco transparentes en la contratación de los proyectos petrolíferos y en el gasto de los ingresos obtenidos, lo que favorece conductas de corrupción que pueden devenir endémicas.

- El síndrome del «maná caído del cielo», que se observa en los países en los que un volumen significativo de los ingresos petrolíferos es objeto de reparto entre la población sin ninguna contrapartida, puede llevar a que esta renta se convierte en una forma de vida. En consecuencia, estos países se ven obligados a importar del exterior el capital humano y empresarial necesario para avanzar en su desarrollo económico, profundizando su dependencia de los mercados exteriores.

A pesar de que este trabajo ha puesto de manifiesto una relación inversa entre los niveles de riesgo-país y la dependencia energética en la mayoría de las regiones, en algunos países la producción y exportación de energías fósiles ha constituido una historia de éxito. Tal es el caso de Malasia, Emiratos Árabes Unidos (Dubai, sobre todo), México, Indonesia y países avanzados como Estados Unidos, Reino Unido, Noruega y Canadá (Schubert, 2012). Estos países han sabido poner en marcha políticas de neutralización de los factores ya señalados que conducen al deterioro de la estructura económica y política como consecuencia de la abundancia de recursos energéticos.

\section{Recomendaciones de política}

A continuación, se citan algunas políticas que los gobiernos de los países productores y exportadores de energías fósiles podrían acometer para mejorar sus niveles de riesgo-país, sobre todo en el caso de los países emergentes y en desarrollo: 
- Actuaciones para mejorar la confianza de la comunidad internacional en la seguridad de las inversiones exteriores y la devolución de la deuda externa, como la mejora de la seguridad jurídica y del clima de negocios, la aplicación del trato nacional a las inversiones extranjeras, la reducción del endeudamiento público y privado, el incremento de la base impositiva, la reducción de los subsidios al consumo energético y a otros bienes de consumo, y la mejora de la cultura de pago de la deuda (Iranzo, 2008).

- Inversión en proyectos de desarrollo (infraestructuras, educación) de los ingresos por la venta de los recursos energéticos, ayudando así a la diversificación sectorial de la economía, tal y como se ha propuesto, por ejemplo, el gobierno de Arabia Saudí en su Programa Visión 2030.

- Creación de un fondo soberano nutrido con los ingresos por exportación de recursos energéticos, y gestionado profesionalmente, con objeto de amortiguar los vaivenes en los ingresos por exportación y generar un depósito de riqueza que permita realizar la transición hacia un futuro en el que los recursos energéticos se hayan agotado.

- Establecimiento de reglas fiscales, al estilo de Chile, que limiten el déficit público en términos estructurales (Frankel, 2012).

- Establecimiento de una política de tipo de cambio que permita evitar la enfermedad holandesa, que comporte un estricto control de la inflación, con objeto de poder hacer frente a la apreciación de la moneda que suele acompañar a las exportaciones de recursos naturales.

- Aumento de la transparencia de los contratos de venta de recursos naturales, mediante la participación en iniciativas, como la Extractive Industries Transparency Initiative (EITI) o el movimiento Publish What You Pay (Schubert, 2006).

- Distribución entre la población, de forma igualitaria (per cápita) de los ingresos por la venta de los recursos naturales -caso de Alaska- (Schubert, 2012).

- Impulso de los contratos de joint venture (tipo concesiones a production sharing), entre las empresas estatales (National Oil Companies, NOCs) y las compañías extranjeras para la exploración y producción de las reservas de energías fósiles. Esto implica definir un marco legal y fiscal que atraiga la inversión extranjera en este sector, procurando garantizar una rentabilidad adecuada a las inversiones de las compañías energéticas extranjeras al tiempo que el país anfitrión obtiene un excedente suficiente (Iranzo y Carrasco, 2008).

- Cobertura del riesgo de los ingresos por exportación de energías fósiles en los mercados de opciones (Frankel, 2012), como hace por ejemplo México (Bloomberg, 2016). 


\section{Conclusión}

A lo largo de este trabajo, se ha intentado dar respuesta a la pregunta de si la explotación de energías fósiles permite mejorar las calificaciones de riesgo-país. Para ello se ha estudiado el comportamiento de los indicadores de riesgo-país y de dependencia energética, agrupando los países en siete regiones diferenciadas del mundo.

En primer lugar, se ha estudiado, a lo largo de un periodo de dieciséis años (20002015), si el riesgo-país medio del grupo de países con dependencia del exterior en energías fósiles ha sido mayor o menor que la media del grupo de países no dependientes (aquellos con más del 80 por 100 de autosuficiencia en energías fósiles y, en general, los exportadores de estas energías). La conclusión obtenida ha sido que el grupo de los países no dependientes a lo largo del periodo han obtenido mejores calificaciones de riesgo-país (medido de dos maneras alternativas) que el grupo de los países dependientes en cada región geográfica. La única excepción es Latinoamérica, donde los países dependientes mantienen en promedio mejores calificaciones de riesgo-país debido, al menos en parte, a su mejor calidad de la gobernanza.

En segundo lugar, se ha realizado un análisis econométrico para comprobar si el grado de dependencia energética de los países en su consumo de energías fósiles (medido por el cociente entre producción y consumo de estas energías) influye sobre sus calificaciones de riesgo-país. El análisis se ha efectuado para el periodo 20002014 y para las mismas regiones que en el análisis anterior.

La principal conclusión del análisis econométrico es que se aprecia un impacto positivo y significativo entre la dependencia de energías fósiles y el riesgo-país, de forma que un incremento en la autosuficiencia en energías fósiles aumenta el riesgo-país. Estos resultados sugieren por tanto una evidencia a favor de la teoría de la «maldición de los recursos» en el caso de las energías fósiles.

Para prevenir y mitigar esta «maldición», se requieren políticas públicas de transparencia y de buena gobernanza en la gestión de los gobiernos de los países productores, un marco contractual y fiscal estable para el desarrollo de la explotación de las reservas, el establecimiento de fondos soberanos para atenuar la volatilidad de los ingresos públicos, políticas tendentes a la diversificación sectorial de la economía, y en general unas políticas macroeconómicas que estimulen la inversión y la estabilidad presupuestaria.

La aparición de importantes descubrimientos de reservas de energías fósiles en los últimos años, principalmente petróleo y gas, en países que hasta la fecha no conocían ninguna dotación de reservas (tales como Tanzania, Mozambique, Senegal, Kenia, Chipre, Israel, Guayana, entre otros) implica que estos países se incorporarán en los próximos años al grupo de países productores y ofertantes de estas materias primas en el ámbito internacional, por lo que la discusión sobre la «maldición de los recursos» seguirá encima de la mesa durante largos años. 


\section{Referencias bibliográficas}

[1] AHUJA, A.; WISEMAN, K. y SYED, M. (2017). Assessing Country Risk-Selected Approaches. Fondo Monetario Internacional. Reference Note. Strategy, Policy and Review Departement.

[2] BLOOMBERG (2016). «Mexico's 2017 Oil Hedges Lock in \$9.5 Billion Value: Takeaways». Recuperado en agosto de 2016. https://www.bloomberg.com/news/ articles/2016-08-29/mexico-s-2017-oil-hedges-lock-in-9-5-billion-value-takeaways

[3] BRITISH PETROLEUM (2001-2016). BP Statistical Review of World Energy. Informes de los años 2001 a 2016. Recuperados entre julio y agosto de 2016. www.bp.com.

[4] COMISIÓN EUROPEA (2017). «Estrategia de seguridad energética». Recuperado en julio de 2017. https://ec .europa.eu/energy/en/topics/energy-strategy-and-energy-union/ energy-security-strategy.

[5] FINANCIAL TIMES (2016). «Definition of EMBI». Recuperado en julio de 2017. http://lexicon.ft.com/Term?term $=E M B I \& m h q 5 j=e 3$.

[6] FITCH RATINGS. Recuperado en julio de 2016. https://www.fitchratings.com/site/ home.

[7] FONDO MONETARIO INTERNACIONAL (2012). «Macroeconomic Policy Frameworks for Resource-Rich Developing Countries». Recuperado en julio de 2017. https://www.imf.org/external/np/pp/eng/2012/082412.pdf.

[8] FONDO MONETARIO INTERNACIONAL (2017). World Economic Outlook, April 2017, pp. 206-209.

[9] FRENKEL, J.A. (2012). «The Natural Resource Curse: A Survey of Diagnoses and Some Prescriptions». Faculty Research Working Paper Series. RWP12-014. Harvard Kennedy School and NBER.

[10] FONDO MONETARIO INTERNACIONAL. Global Financial Stability Report. Números de los años 2001 a 2016. Tabla sobre «Emerging Market Bond Index: EMBI Global Yield Spreads».

[11] HAYAKAWA, K.; KIMURA, F. y LEE, H. (2011). «How Does Country-Risk Matter For Foreign Direct Investment?»IDE Discussion Paper No. 281. Recuperado en junio de 2017. http://www.eria.org/ERIA-DP-2012-03.pdf.

[12] HUMPHREYS, M.; SACHS, J. D. y STIGLITZ, J. E. (2007). Escaping the Resource Curse, en M. Humphreys, J. D. Sachs y J. E. Stiglitz (eds.). Columbia University Press.

[13] INSTITUT FRANÇAIS DU PÉTROLE (2016). «Nouvelles découvertes conventionnelles de pétrole et de gaz». Panorama 2016.

[14] INTERNATIONAL ENERGY AGENCY. World Energy Outlook, 2016, pp. 58-105.

[15] IRANZO, S. (2008). «Introducción al riesgo-país. Documentos Ocasionales 0802. Banco de España.

[16] IRANZO, S. y CARRASCO, C. (2008). «La situación energética en Latinoamérica». Boletín Económico, febrero. Banco de España, 2, pp. 73-85.

[17] MANKIW, N. G. (2015). Principles of Economics. Seventh Edition. United States. Cengage Learning.

[18] MOODY'S. Recuperado en julio de 2016. https://www.moodys.com/researchandratings/ market-segment/sovereign-supranational/.

[19] NEAL, L. y CAMERON, R. (2016). A Concise Economic History of the World. Fifth Edition. Oxford University Press. 
[20] NEWEY, W. y WEST, K. (1987): «A Simple Positive Semi-definite, Heteroskedastic and Autocorrelation Consistent Covariance Matrix». Econometrica, 55, 3, 703-708.

[21] OCDE. (2015). «Country Risk Classification.» Recuperado en julio de 2016. http:// www.oecd.org/trade/xcred/crc.htm.

[22] ORGANIZACIÓN MUNDIAL DEL COMERCIO (2017). «Overview». Recuperado en julio de 2017.https://www.wto.org/english/thewto_e/whatis_e/wto_dg_stat_e.htm.

[23] PEÑA, E. A. y SLATE, E. H. (2006). «Global validation of linear model assumptions». Journal of the American Statistical Association, 101, 473, pp. 341-354.

[24] SCHUBERT, S. R. (2006). «Revisiting The Oil Curse: Are Oil Rich Nations Really Doomed to Autocracy and Inequality?». National Defense Academy in Austria. Institute for Human and Social Studies.

[25] STANDARD \& POOR'S. «S\&P Global Ratings». Recuperado en julio de 2016. https:// www.standardandpoors.com/en_US/web/guest/ratings/ratings-actions.

[26] STIGLITZ, J. E. (2012). «From Resource Curse to Blessing». Project Syndicate. July $7^{\text {th }}$.

[27] STOCK, J. H. y WATSON, M.W. (2012). Introducción a la Econometría, 3. a ed., Madrid, Pearson Educación.

[28] THE WORLD BANK. Data. «Energy imports, net (\% of energy use)». Recuperado en julio de 2017. http://data.worldbank.org/indicator/EG.IMP.CONS.ZS.

[29] THE WORLD BANK. Data. «Fuel Exports (\% of merchandise exports)». Recuperado en julio de 2017. http://data.worldbank.org/indicator/TX.VAL.FUEL.ZS.UN.

[30] THE WORLD BANK. Data. «GDP (current US\$)». Recuperado en julio de 2017. http://data.worldbank.org/indicator/NY.GDP.MKTP.CD.

[31] THE WORLD BANK. WORLDWIDE GOVERNANCE INDICATORS. Informes de los años 1996 a 2015. Recuperado en julio de 2017. http://data.worldbank.org/data-catalog/worldwide-governance-indicators.

[32] VAN DER PLOEG, F (2011). «Natural Resources: Curse or Blessing?». Journal of Economic Literature, 49, 2, 366-420.

[33] VENABLES, A. J. (2016). «Using Natural Resources for Development: Why Has It Proven So Difficult?». Journal of Economic Perspectives, 30, 1, 161-184. http://pubs. aeaweb.org/doi/pdfplus/10.1257/jep.30.1.161 